\title{
Do Citizens use Sociodemographic Characteristics as Cues to Infer Candidate Issue Positions?
}

\author{
Thomas Däubler $^{1}$;* (1) | Franziska Quoß ${ }^{2}$ (1) | Lukas Rudolph $^{3}$ (1)
}

${ }^{1}$ University College Dublin, Ireland

${ }^{2}$ ETH Zurich

${ }^{3}$ LMU Munich and ETH Zurich

\section{Correspondence}

Thomas Däubler, University College Dublin, School of Politics and International Relations, Belfield, Dublin 4, Ireland.

Email: thomas.daubler@ucd.ie

Funding information

Swiss Federal Office of the Environment (FOEN)

\begin{abstract}
In open-list proportional representation systems, choosing candidates based on issue proximity can improve policy congruence. However, in practice, voters may not know enough about individual candidates to do so. Hence, we examine whether voters infer individual positions from cues provided on ballots, namely age and residence. Studying the Swiss parliamentary elections of 2019, we focus on environmental policy, both a very salient issue and featuring considerable intra-party heterogeneity of positions. We combine comprehensive candidate data with a representative voter survey and conduct a survey-embedded experiment $(N=10,758)$. We find that citizens have indeed little knowledge of candidate positions. However, ballot cues predict policy differences among candidates within parties only to a limited extent, and the experiment does not suggest that voters use ballot information to predict positions directly. Instead, as suggested by additional analyses, citizens may perceive candidates who resemble their own sociodemographic profile as having positions closer to their own.
\end{abstract}

\section{Zusammenfassung}

In Verhältniswahlsystemen mit offenen Listen kann die Wahl von KandidatInnen anhand ihrer inhaltlichen Nähe die Politikkongruenz verbessern. In der Praxis wissen WählerInnen jedoch möglicherweise nicht genug über

\footnotetext{
*The order of authors follows alphabetical convention. Contributions were equal.
}

This is an open access article under the terms of the Creative Commons Attribution-NonCommercial-NoDerivs License, which permits use and distribution in any medium, provided the original work is properly cited, the use is non-commercial and no modifications or adaptations are made.

(C) 2021 The Authors. Swiss Political Science Review published by John Wiley \& Sons Ltd on behalf of Swiss Political Science Association. 
einzelne KandidatInnen. Wir untersuchen daher, ob WählerInnen die Issue-Positionen aus Stimmzettelinformationen, insbesondere Alter und Wohnort, ableiten. Wir analysieren im Kontext der Schweizer Parlamentswahlen von 2019 die umweltpolitische Dimension, die bei dieser Wahl sehr wichtig und gleichzeitig von hoher parteiinterner Heterogenität der Issue-Positionen geprägt war. Wir kombinieren umfassende KandidatInnendaten mit einer repräsentativen Umfrage und führen ein Umfrageexperiment durch $(N=10.758)$. Wir zeigen, dass WählerInnen tatsächlich wenig über die Positionen der KandidatInnen wissen. Allerdings lassen sich politische Unterschiede zwischen KandidatInnen einer Partei nur begrenzt durch Stimmzettelinformationen vorhersagen, und die Ergebnisse des Experiments deuten nicht darauf hin, dass WählerInnen diese Angaben systematisch so nutzen. Stattdessen legen zusätzliche Analysen nahe, dass WählerInnen KandidatInnen mit einemihnen ähnlichen soziodemografischen Profil näher an ihrer eigenen Position verorten.

\section{Résumé}

Dans les systèmes de représentation proportionnelle á liste ouverte, le choix des candidat(e)s en fonction de la proximité regardant des enjeux peut améliorer la congruence des politiques. Cependant, les électeurs/électrices n'en savent pas forcément assez pour le faire. Nous examinons la déduction des positions á travers des indices sur les bulletins de vote, notamment l'âge et la résidence. Les élections parlementaires suisses de 2019 portaient sur la politique environnementale, un enjeu accompagné d'une hétérogénéité intra-partisane considérable. Nous relions des données sur les candidat(e)s avec une enquête représentative comprenant une expérience ( $N=10$ 758). Les citoyen(ne)s connaissent effectivement peu les positions des candidat(e)s. Pourtant, les indices prédisent les différences intra-partisanes de façon limitée et l'expérience ne suggère pas que les électeurs/électrices utilisent les indices pour prédire les positions. Des analyses supplémentaires suggèrent plutôt que les citoyen(ne)s perçoivent les candidat(e)s ressemblant leur profil sociodémographique comme ayant des positions plus proches des leurs.

\section{K E Y W O R D S}

cues, environmental policy, heuristics, open-list PR, political knowledge, survey experiment 


\section{INTRODUCTION}

Under open-list proportional representation (OLPR) systems, as also used in Swiss National Council elections, voters can express preferences for individual candidates in a very flexible way (Bühlmann et al., 2016; Selb \& Lutz, 2015). In principle, this institutional setting creates plenty of opportunities for choosing candidates on the basis of their policy positions, which is particularly relevant for issues cutting across party lines (Blumenau et al., 2017; Bräuninger et al., 2021). In practice, however, this requires voters to be well-informed about candidates' policy views. Given that many citizens already struggle to locate political parties on specific issue dimensions (Banducci et al., 2017; Dahlberg \& Harteveld, 2016), it may be unrealistic to expect sufficient information on policy positions of candidates. Voting-advice applications like the Swiss "Smartvote" (Fivaz \& Nadig, 2010; Ladner et al., 2012) may offer a remedy (Schultze, 2014; Munzert et al., 2020; but see Heinsohn et al., 2019), but they require some active investment of time and effort by voters. In contrast, information regarding the sociodemographic background of a candidate is typically printed on the ballot paper along with the party affiliation. ${ }^{1}$ Hence, it is readily available and could serve as a low-level cue (Arnesen et al., 2019; Brockington, 2003; McDermott, 1997, 1998; Popkin, 1991), in this case to predict the political views of individual candidates running for the same party. We address three interrelated questions. Most generally, do voters use candidate information - in our case age and residence - to predict the position of candidates on a specific policy dimension? Because of its saliency and the considerable intra-party heterogeneity of views, our study focuses on environmental policy. In this context, we further ask whether citizens should rely on such candidate demographics, and whether some subgroups are more likely to use these cues compared with others.

People may learn about general associations between sociodemographics and attitudes in their everyday personal encounters with other citizens or from media exposure. There, for example, young people play a driving role in the "climate strike" movement. And indeed, data we analyze below show that in the Swiss population younger people have "greener" views than older citizens. However, such patterns are not necessarily useful, and possibly even misleading, for inferring differences for candidates after taking into account their party affiliation (Carnes \& Sadin, 2015), which in real-world elections is almost always known. It is therefore an empirical question itself whether these variables predict variation within parties and thus are valid cues for gauging intraparty differences. After answering that question, we engage with existing debates on the use of heuristics (Dancey \& Sheagley, 2013; Fortunato \& Stevenson, 2019; Redlawsk \& Lau, 2013) and examine whether voters with high political interest are more or less likely to use cues.

The Swiss election of 2019 featured something akin to a "Green revolution", with a very prominent role of environmental topics during the campaign, and large gains by the strongly pro-environment Green Party (GP) and Green Liberal Party (glp) (Bernhard, 2020). As the other major Swiss parties show considerable intra-party heterogeneity on environmental protection policy, knowing about candidates' positions on this dimension would have been worthwhile information for many voters.

To examine whether citizens do and should use such cues, we combine two comprehensive data sources. First, the Smartvote (Smartvote, 2019b) voting-advice application provides information on almost all candidates' sociodemographics and environmental issue positions. Second, within a large representative survey of the Swiss population, we conducted an experiment. Fielded only shortly after the 2019 elections, we presented real candidates to respondents, while randomly exposing some of them to information about candidates (age and residence) and parties (position of median candidate).

\footnotetext{
${ }^{1}$ We focus on candidate age and residence, in particular. Note that these may not be the best possible sociodemographic predictors of the environmental position of candidates. However, their wide availability to voters makes them promising cues for overcoming the information shortage.
} 
In the experiment, we then asked respondents to assess the degree to which candidates would like to expand environmental protection. We analyze whether the provision of candidate information affects whether participants fulfil this task, i.e. whether they feel sufficiently confident to locate a candidate on the policy scale, and, if they do, where on the scale they placed her/him. This set-up allows us to mimic the challenge for citizens to infer candidate positions in an actual election, with plausible levels of information. At the same time, we can measure and control for prior exposure of respondents to the candidates. Hence, our results should have high external validity.

We report three core findings. First, knowledge of candidate positions on the "green" dimension was quite limited among voters - despite the prominence of the issue in the election. Hence, it is worthwhile to examine whether candidate cues could help to fill those gaps. Second, we show that the association between age or residence and environmental attitudes in the general population is in the expected direction: younger and urban respondents are reporting "greener attitudes". At the level of the candidates, we find that age and residence differentiate positions only within some parties. As a consequence, these cues can, in practice, be misleading. Third, we turn to the question as to how citizens use these cues. Our experiment reveals on the one hand that citizens become more confident about locating a candidate on the $0-10$ policy position scale when cues are revealed. This effect is particularly pronounced among citizens with low levels of political interest and no prior knowledge of the candidate. On the other hand, across candidates and respondents, we find little evidence that citizens make unidirectional use of the age or residence cues to infer the position of Swiss candidates on the environmental dimension. We find no consistent pattern that younger or more urban candidates are rated greener on average, irrespective of prior candidate knowledge, candidate party affiliation or respondent levels of political interest. However, further exploratory analysis indicates that ballot cues might not be irrelevant after all: when the experiment reveals to respondents that a candidate resembles them in terms of age and residence, they tend to place the candidate closer to their own point of view - irrespective of whether the respondent's stance is strict or lenient on environmental policy. We interpret this as tentative evidence for projection effects, which we deem to be a promising route for future research.

These results allow for both pessimistic and optimistic conclusions. On the one hand, in the case of the environmental dimension in Switzerland, there was limited scope of using such demographics fruitfully to gauge intra-party variation in the first place. On the other hand, citizens at least do not appear to apply ballot-level candidate information in combination with stereotypes that are misleading. A more general lesson is that whether sociodemographics can (and should) be used to fill knowledge gaps about candidate positions depends on the context, i.e. on the policy issue at hand and on what explains variation in respective positions within parties. Beyond that, further research needs to address to what extent effects resulting from a self-resemblance heuristic may help or harm.

\section{PLENTY OF CHOICE - ENOUGH INFORMATION?}

OLPR systems offer voters ample choice. Citizens can select candidates within parties from comparatively long lists, and in Switzerland the panachage option does not even require a voter to restrict support to politicians of just one party (Bühlmann et al., 2016; Selb \& Lutz, 2015). In principle, these electoral rules provide an ideal ground for choosing a set of candidates that share a voter's views, even in a complex policy space with multiple issue dimensions (Kurella \& Rosset, 2018).

Suppose you have fairly rightist views on a public spending versus low taxation dimension but lean towards the left end on an environmental protection versus economic growth axis. In a single-member plurality or closed-list electoral system, for example, the choice of party and candidate(s) is coupled, and whether it is possible to find a matching choice depends on the set 
"menu". Finding candidates that share your combination of issue positions should typically be easier under OLPR, also because vote-seeking parties are incentivized to offer candidates with a broad range of views (Matakos et al., 2018; Tromborg, 2021).

Recent work suggests that some voters can even be induced to switch parties under open rather than closed lists, because this change allows them to support specific candidates who share their view on a cross-cutting issue (Blumenau et al., 2017; Bräuninger et al., 2021). These studies rely on survey-embedded experiments, which provide information on positions of (fictitious) candidates as part of the treatment. The big question here is how well the results travel to a real-world setting where voters need to acquire knowledge of candidate positions themselves.

Limited knowledge regarding policies even at the party level, the cost of collecting information, and the large number of candidates under OLPR suggest that one should be sceptical. A number of studies demonstrate considerable causal effects of ballot position on candidate performance under OLPR (Blom-Hansen et al., 2016; Däubler \& Rudolph, 2020; Faas \& Schoen, 2006), and a statistical association has also been found in the Swiss case (Lutz, 2010). Other work points to the important role of factors like being local (Shugart et al., 2005), an incumbent (Dahlgaard, 2016; Mustillo \& Polga-Hecimovich, 2020) or a celebrity (Arter, 2014). Together, these results suggest that candidate choice under OLPR is strongly influenced by easily observable candidate features rather than shared policy views.

On the other hand, this need not mean that there is no place for policy considerations at all. Von Schoultz and Papageorgiou (2019) report that having moderate positions within the party (on each of an economic and a cultural policy dimension) had a positive association with the personal vote in the Finnish 2015 OLPR elections. Population survey data referring to the same election show that voters with high levels of political knowledge or online media attention are more likely to state that issue positions mattered for their candidate choice (Coffé \& von Schoultz, 2020). Hence, voting advice applications, like Smartvote in Switzerland (Fivaz \& Nadig, 2010; Ladner et al., 2012), may assist people in finding candidates that are close to them in policy space (e.g., Heinsohn et al., 2019; Munzert et al., 2020; Schultze, 2014). Still, this does require an effort on part of the voter.

An alternative solution to the information problem could lie in the use of heuristics (Gigerenzer \& Gaissmaier, 2011; Lupia \& McCubbins, 1998). Even if voters do not know candidates' positions, they may be able to infer them based on candidate features that are readily available. In other words, they can use cues to "guesstimate" the missing information (Conover \& Feldman, 1989; McDermott, 1997; Popkin et al., 1976). Sociodemographic characteristics of candidates are suitable as predictors, particularly if they are printed on the ballot paper and thus on hand for everyone (Brockington, 2003). ${ }^{2}$ From a psychological perspective, by ascribing positions based on group membership, voters use stereotypes, which may be based on observed evidence but can be biased (Hilton \& Von Hippel, 1996; McGarty et al., 2002).

There is evidence that voters use candidate sociodemographics to infer candidate policy positions, with research mainly focusing on the role of gender in the context of US politics (e.g., Huddy \& Terkildsen, 1993; Koch, 2000; McDermott, 1997, 1998; but see Devroe \& Wauters, 2018, on Belgium). With regard to Europe, we are aware of two studies that are closely related to our interest (Arnesen et al., 2019; Pedersen et al., 2019), both of which examine the interplay of candidate characteristics and policy positions relying on an experiment with a conjoint design. In the Danish context, Pedersen et al. (2019) present candidate descriptions varying three types of social background characteristics and information on a binary pension-policy issue (no information, left-leaning view, right-leaning view). Among other things, participants are asked to rate the candidates on an eleven-point economic left-right scale. Parents' class background and occupation of the candidate affect these ratings, but much less so if the issue position is provided.

${ }^{2}$ In the Swiss case, gender, party affiliation and place of residence are always communicated to voters, and age is displayed in most cantons (which comprise more than $80 \%$ of the population). 
Based on data from Norway, Arnesen et al. (2019) report similar findings. In a first experiment, they show that candidate characteristics become less important for choosing between candidates when their policy positions on three issues are also revealed. In a second experiment, participants are asked to state which of two candidates - described on seven sociodemographic dimensions - agrees most with a given issue statement. They do employ the information in the task; particularly interesting for our purpose is that citizens use associations that also predict attitudes in the wider population. ${ }^{3}$ Our interest is related in the sense that we would also like to know whether candidate characteristics are used to infer positions. However, while also relying on a survey-embedded experiment, we create a setting that aims at high external validity by approaching the situation of a real-world election. Specifically, we present real candidates from recent elections rather than fictitious politicians (which allows us to take into account the effects of prior exposure to these candidates); we include information on party affiliation (which is almost always present when judging politicians in practice); and we provide candidate information akin to that printed on a ballot paper (which is available to all voters).

\section{WHEN CAN (AND SHOULD) VOTERS USE SOCIODEMOGRAPHICS TO INFER POLICY POSITIONS?}

Can voters use sociodemographics to infer positions of individual candidates on a secondary dimension in a real-world context of OLPR elections? If most people do not acquire such knowledge during the campaign, cues printed on ballot papers could constitute a heuristic solution to impute the missing information. Citizens can use associations between candidate characteristics and policy views they have "learned". For example, if I have come to believe that younger people tend to care more about environmental protection than older citizens, I may predict that a candidate has fairly "green" views, only from knowing that the politician is young. In the psychological literature, such beliefs are referred to as stereotypes (Hilton \& Von Hippel, 1996; McGarty et al., 2002). Relying on stereotypes can be problematic when bias exists (e.g., owing to selective exposure to certain subgroups of young people), or such beliefs are not based on objective evidence at all.

Then, in order to use age or residence as a cue for inferring the policy position of a candidate, two conditions must be met: first, citizens infer such differences and store related information; and, second, they access and use this information when an inference about a group member's position is required. Note that in the first step, there are different ways of observing, and that may also affect whether and how categorization takes place, stereotypes are formed, and, as a result, whether they are correct. Direct personal contact is a first channel. As Popkin et al. (1976: 794) put it: "Demographic characteristics (e.g., race, ethnicity, age) are important cues because the voter observes the relationship between these traits and behavior as part of his daily experience." When communicating with other citizens, citizens may realize that, for example, younger people have "greener" attitudes. A second channel is indirect. Actors - typically but not necessarily political ones - make statements in the media. Readers, listeners and watchers could experience younger actors more frequently express green views than older ones.

There are at least two potential differences across these channels. First, the nature of the process creating potential selectivity varies. Personal circumstances and decisions affect who people interact with directly, while news exposure depends both on what people choose and what media outlets present. Second, the role of partisanship is different. In mediated communication, information on party affiliation is more likely to be present and prominent (compare watching a politician on a talk show to having a conversation with a work colleague over lunch), which may suppress the role of other cues. In principle, it is possible that people learn about associations while "controlling" for

${ }^{3}$ This is corroborated by a no-difference finding for an additional treatment, framing the task as either showing two "politicians" or "persons" (Arnesen et al., 2019: 51). 
party affiliation also in citizen-to-citizen communication (do younger people have "greener" views regardless of party affiliation?), but this may in practice be too demanding a task.

Recent events and more general patterns underlying environmental attitudes suggest that sociodemographics could serve as cues to fill knowledge gaps about candidate positions. The sociodemographic cue that is most clearly connected to environmental attitudes is gender (Egan \& Mullin, 2017: 215). However, as we provide respondents with real candidate names, we do not experimentally vary candidate sex and therefore focus on two other aspects.

The first of these is age. Previous literature predominantly finds that older people tend to show less environmental concern than younger ones, either owing to age or cohort effects (e.g., Poortinga et al., 2019; Mohai \& Twight, 1987; but see Franzen \& Vogl, 2013). Theoretically, these differences can be explained by higher levels of post-materialist values among younger people (Echavarren, 2017; Inglehart, 1995), by stronger support for more far-reaching societal changes (Van Liere \& Dunlap, 1980) or by cohort effects linked to varying exposure to emerging environmental movements in the 1970s and 1980s (Franzen \& Meyer, 2010).

In the case of Switzerland and regarding current events, the climate strike is often depicted as a youth movement. For example, Bernhard (2020: 1341) explains: "Since the end of 2018, Switzerland witnessed an unprecedented mobilisation over climate change. Inspired by Greta Thunberg, a Swedish climate activist, school children and younger adults staged numerous events, such as student strikes, across the country." The prominent presentation of the climate change protests as a movement of younger people may contribute to a close connection between age and environmental attitudes in people's minds, even if the link between these variables in a random sample of the population is modest or even absent.

The second sociodemographic cue that we focus on is the level of urbanity, as communicated via the home town of the candidate. The underlying relationship here is that urban citizens tend to have higher levels of environmental concern (Buttel, 1992; McMillan et al., 1997). Early explanations for this link argue that urban dwellers are more strongly affected by environmental pollution, whereas rural residents are more likely to earn a living from conventional agriculture, which may be at odds with environmental protection (McMillan et al., 1997). This view could be reinforced by agricultural interest groups opposing certain environmental measures (Humbel, 2021). In addition, similar as for age, urban residents may more frequently hold post-material values (Carmines \& Layman, 1997).

We therefore formulate the following hypotheses:

Hypothesis 1 Receiving information on candidate age and residence increases the probability that the candidate is placed on the environmental policy scale.

Hypothesis 2 A candidate who is known to be older or from a rural background is rated as less in favour of environmental protection.

The above arguments and analysis of patterns in citizens' and candidates' policy preferences raise further important points, which mirror broader debates regarding the use of heuristics (Bowler \& Nicholson, 2018; Redlawsk \& Lau, 2013). First, using candidate age and residence as predictors may require at least an intuition about the underlying association between these variables and policy views. The second point concerns whether heuristics should be used, i.e. whether heuristic strategies can actually help to fill in the missing information. In the context of real elections (and also in our experiment, which emulates ballot-paper information), party affiliation is known. Therefore, if the sociodemographics do not differentiate the policy positions among candidates within parties in line with the stereotypes that people have formed, they will not be useful and possibly even be misleading. The question then becomes whether people know enough about when to rely on cues and when to stay clear of them. Dancey and Sheagley (2013) suggest that the most interested citizens are most likely to use heuristic strategies and therefore also most likely to be misled by cues "gone bad". In contrast, Fortunato 
and Stevenson (2019) argue that this group knows enough to use cues only in those situations when they are helpful. Which of these views holds likely depends on the nature of the inference problem and that of the cue. In our setting, we tend towards the former expectation. For the citizens, judging in which parties intra-party heterogeneity of environmental views is linked to sociodemographics and in which it is not proves difficult in itself. Therefore, we would expect that very few citizens would know or have an intuition about when (not) to use the cues.

Hypothesis 3 Citizens with a stronger political interest are more likely to use the candidate information cues.

\section{CONTEXT: 2019 ELECTIONS TO THE SWISS NATIONAL COUNCIL}

In the vast majority of Swiss cantons, elections to the National Council are conducted using an OLPR electoral system. ${ }^{4}$ The OLPR system gives voters a lot of choice: depending on their canton, they have up to 35 votes (Zurich), which may be allocated to individual candidates (up to two votes) from multiple parties. As reflected in our survey data, a large share of voters makes use of these opportunities: out of the 6499 respondents $(62.8 \%$ of the sample) who report that they voted in the last election, $2323(35.9 \%)$ choose a party list as given, while $1396(21.6 \%)$ split their ticket and 1871 (28.9\%) hand in one party list but change it. ${ }^{5}$

Environmental and climate topics played an important role in the national election of 2019 (Bernhard, 2020). The Swiss Radio and Television (SRF) coined it the "Climate Election" (SRF, 2019). Neue Zürcher Zeitung, one of the most-read quality newspapers in Switzerland, called it a "Green Triumph" and regarded the changes in party strength in the usually very stable National Council as a landslide (Hehli \& Thelitz, 2019). Also, among our respondents, more than half mention "environmental protection/climate change" among the top three societal problems in Switzerland, and more than a quarter consider the aforementioned to be the most important problem. Hence, we focus on a particularly interesting case for our argument. We study a policy issue that has only recently gained in salience among large segments of the electorate. Knowledge of candidate positions is thus relevant to the choice of many voters but not necessarily widespread. In addition, environmental protection in the Swiss context is a cross-cutting issue, since there is considerable heterogeneity of views within parties.

Figure 1 shows the distribution of candidates' positions on environmental protection, both across and within parties. The environmental scores are based on the Smartvote vote-advice application (Smartvote, 2019b). We use the answers of 3993 candidates ( $84 \%$ of all candidates for the National Council and 91\% of all candidates for the Council of States [Smartvote, 2019a, c]) on the 14 items related to the environment. The index is calculated as the mean score of all answers given.

To calculate the respondents' environmental score, our survey included the five survey questions that Smartvote also uses to calculate the Environmental Score in the "rapid" version of their application. Item lists and results from validity checks are reported in Appendix Section A.5. Apart from the Social Democratic Party (SP) and the green parties glp and GPS, in which the large majority of candidates have high scores on the environmental dimension, we can see a rather large spread of candidates' positions (see also Appendix Table A.2). This also results in overlap between these parties.

\footnotetext{
${ }^{4}$ In the experiment, we also include respondents from (very small) cantons with a majoritarian electoral system: Uri, Obwalden, Nidwalden, Glarus, Appenzell A. Rh., Appenzell I. Rh. (2.8\% of respondents).

${ }^{5}$ The remaining $13.7 \%$ report not to know how they voted.
} 


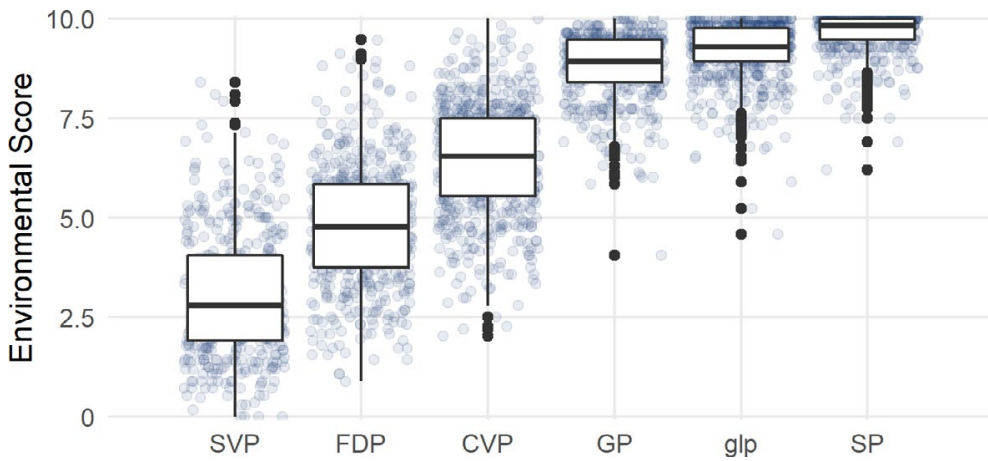

F I G U R E 1 Heterogeneity of candidates' environmental score within and across parties.

Notes: Scale runs from 0 (no expansion of environmental protection) to 10 (expansion of environmental protection). Score is based on four-categorical candidate (dis)agreement to multiple issue questions (Smartvote, 2019b).

SVP = Swiss People's Party, FDP = Free Democratic Party, CVP = Christian Democratic People's Party, GP = Green Party, glp = Green Liberal Party, SP = Social Democratic Party

\section{RESEARCH DESIGN}

The survey experiment was embedded in the fourth wave of the Swiss Environmental Panel, a large panel study that has been running since early 2018 (Rudolph et al., 2021). This wave was fielded between November 18, 2019, and February 2020 , ${ }^{6}$ i.e. starting approximately one month after the national election in Switzerland. Respondents could choose whether to take part online or via pen and paper. The address sample was provided by the Swiss Federal Statistical Office (BfS) and is representative of the Swiss resident population aged 17 and older. ${ }^{7}$ While the survey experiment was implemented in an ongoing panel study, all data used comes from wave four only. For descriptives of our core dependent and independent variables, see Appendix Section A.1. The experiment itself proceeds in two stages. In the first step, we show respondents three prominent candidates from the six nationally competing parties. For each respondent, we restrict the set of displayed candidates to those running in the respondent's canton. To choose prominent candidates, we drew a random sample of candidates among the set of candidates who ran for the Council of States, or the National Council on a top-three list position, or as an incumbent for one of the six major parties. In the baseline condition, respondents see only the name and party affiliation of the candidate. The other experimental arms offer additional information on age and residence (group 2), the party's mean environmental position (group 3) or both of these (group 4). In the next step, we ask respondents to rate each of the three candidates they saw: "How do you rate candidate $X$ ?" "Would (s)he like not to increase environmental protection ( 0 ) or would (s)he like to strongly increase environmental protection (10)?" Finally, respondents indicate whether they know the candidate or not. The full wording of the survey items, including the introductory text and the layout of the questions in the print questionnaire, is presented in Appendix Section A.6. As our experiment presents respondents with candidates who did run in their district in an election that just took place, it closely mirrors the situation of placing candidates on policy dimensions in the process of making a voting

\footnotetext{
${ }^{6}$ The vast majority of respondents completed the survey in December 2019.

${ }^{7}$ The wave used coincided with a panel refreshment. In total, we contacted 21,219 Swiss residents, 3762 of which had already been part of the panel. Out of those, 8280 replied online and 2780 returned the paper questionnaire. The total raw sample comprises 11,060 respondents and closely mirrors the Swiss population on a range of sociodemographic variables. The response rate of the full sample is $78.60 \%$ in the original and $44.70 \%$ in the refreshment sample.
} 
decision in reality. ${ }^{8}$ We focus on visible candidates because we wanted to take into account how effects differ if respondents had some prior exposure to the candidates. The average citizen most likely does not know much about the environmental attitudes of the average candidate, especially in an OLPR system with large lists. A random sample of candidates would likely have provided too little variation to test for effects of prior knowledge. In practice, candidates with ex-ante low profiles also get very few votes. While this design choice makes it harder to find the postulated effect, it increases the practical relevance of our findings.

For the analyses, we link the respondent data to the Smartvote environmental scores for each of the candidates that they saw. In the experiment, the age of candidates is stated directly in their profiles, while the urban versus rural origin is presented indirectly via the place of residence. For the analysis, we distinguish urban, peri-urban and rural candidates by combining zip codes and Swiss Building Zone Statistics (Federal Office for Spatial Development, 2017) categories. ${ }^{9}$

\section{RESULTS}

\section{Baseline knowledge of candidates' environmental positions}

The starting point for our overall question is that citizens' knowledge about candidates' issue positions - more specifically those related to the scope of environmental protection - is likely limited. As a first step, we therefore examine whether this notion is correct, looking at the control group in our experiment, which does not receive any of the treatments (see Appendix Section A.3). We check whether respondents place the candidate at or close to the true score on the $0-10$ scale; $21.3 \%$ of the placements fall within one point of the actual score, and with a less strict criterion of two points the corresponding figure is $40.3 \%$. These figures are close to the agreement one would observe if respondents simply placed candidates randomly. ${ }^{10}$

Note that these figures would already include any persistent knowledge-enhancing effects from prior use of vote-advice applications. In our sample, $13.4 \%$ of respondents state that they had used Smartvote to inform themselves about the national election. ${ }^{11}$ The self-reported Smartvote users do not perform any better in the placement task than other respondents (with $20.0 \%$ and $38.4 \%$, their rates for correct answers are even lower than those among nonSmartvote users). We concede that our procedure for determining the correctness of results is rather crude, and it is possible that people forget learned positions again. However, we believe that we can safely assume that many citizens could benefit from imputing candidate positions based on sociodemographic cues.

\section{Sociodemographics as predictors of environmental positions}

Above, we argued that it is intuitive to assume differences in attitudes towards the environment based on gender, age and place of residence. Do the data support these intuitions, and

\footnotetext{
${ }^{8}$ For feasibility reasons, we depart from the actual setting by mixing candidates for the two chambers and presenting only a subset of parties and candidates to limit the information complexity for respondents. Appendix Section A.2 describes the process of choosing and presenting candidates in more detail.

${ }^{9}$ Communities classified as ‘urban community of a large agglomeration' or 'municipalities of a large or medium-sized agglomeration' (score 1-2) are considered urban; 'municipalities outside of an agglomeration or of a small agglomeration' or 'peri-urban municipalities of high/medium/low density' (score 3-6) are considered peri-urban; and 'rural municipalities centrally, rather centrally or peripherally located' (score 7-9) are considered rural.

${ }^{10}$ The results are very similar when considering only respondents placing all three candidates.

${ }^{11}$ In comparison, the vote-advice application is much less often used as a source of information than newspapers (59.3\%), TV $(55.8 \%)$, radio $(35.6 \%)$, established media channels online $(35.3 \%)$ or personal talks $(33.3 \%)$.
} 
how big are such differences? Table 1 shows the associations between sociodemographic characteristics (male vs. female, younger vs. older, and urban vs. rural) and the environmental policy score of citizens. In line with the idea that people use simple categorizations, we dichotomize age at a cut-off of $45,{ }^{12}$ and we distinguish cities from peri-urban and rural municipalities.

Citizens may form expectations concerning the link between sociodemographic variables and environmental positions in their everyday life, which likely happens on the basis of bivariate patterns. Models 1 and 2 in Table 1 therefore include only one variable at a time, while Model 3 includes all predictors typically available from the ballot paper (age, residence and gender) at the same time. These models show that groups defined by age and residence indeed differ in their environmental attitudes, albeit not very strongly. People aged above 45 years are approximately 0.2 scale points (on a $0-10$ scale) less in favour of environmental protection than those aged below 45. People living in the countryside favour less protection than urban dwellers, by approximately 0.6 scale points. This is about the same as the value for the difference between women and men. There are doubts that citizens factor in party affiliation when forming stereotypes related to sociodemographic groups and environmental attitudes. As Model 4 in Table 1 shows, differences would still be detectable (although smaller in size) even when including party identification as a predictor. ${ }^{13}$ These results suggest, overall, more modest differences linked to age and residence than we may have expected. In practice, however, it is also possible that citizens overestimate such differences. The prominence of the climate strike, in particular, may make many people believe that the younger generation has considerably "greener" attitudes than what is reflected in the actual data.

A different question is whether age and residence should be used as cues for imputing candidate positions. In other words, after party affiliation is taken into account, do these variables predict differences among candidates within parties? Table 2, which resembles Table 1 but refers to associations at the level of candidates, allows us to assess this. The pooled models without (Model 1) and with (Model 2) party affiliation included show very similar results to those for citizens in Table 1 . Models 3-8, however, suggest that age actually does not differentiate among candidates within any of the parties. Residence fails to do so among politicians of the Swiss People's Party (SVP), and in the Free Democratic Party (FDP), politicians from the countryside are actually on average more pro-environmental than their urban colleagues. Hence, if party affiliation is known, and in our experiment emulating ballot-paper information it always is, the heuristics more often than not are ineffective or misleading.

\section{Results of the experiment}

We now turn to the question whether citizens use cues in practice - how does information on candidate age and residence affect (a) whether respondents do locate candidates, and (b) where they place them on the 11-point environmental policy position scale?

From $\mathrm{H} 1$, we expect that revealing heuristics to respondents increases the probability that they locate a candidate. Overall, we find that with the candidate age and residence cue displayed, about

\footnotetext{
${ }^{12}$ We choose an age cut-off of 45 years following visual inspection of a local polynomial smooth plot of environmental score against age (see Appendix Figure A.1). Following a local maximum for people in their late thirties, the curve becomes almost flat for a 15 -year interval above the cut-off of 45 , before sloping downwards further. As a robustness check, we show that the specific choice of the cut-off does not drive our results. The substantive conclusions remain very similar when we systematically shift this cut-off downwards, when we use a three-categorical specification of age, or when we move to a continuous measure (see Appendix Section A.11).

${ }^{13}$ Results are robust in terms of employing Tobit regressions, censoring observed outcomes at 0 and 10.
} 
T A B L E 1 Citizens' environmental score as predicted by demographics

(1)

$-0.239 * * *$

$(0.0488)$

(2)

Age (ref.: 17-45 years)

Above 45

Residence (ref.: Urban)

Peri-urban

Rural

Gender (ref.: Female)

Male

Constant

Control for party identification

$N$

$R^{2}$

10,380
(3)

(4)

$\begin{array}{ll}-0.193^{* * *} & -0.0812^{+} \\ (0.0479) & (0.0431)\end{array}$

$-0.554^{* * *}$

$-0.525^{* * *}$

$-0.302^{* * *}$

(0.0575)

(0.0569)

(0.0511)

$-0.823^{* * *}$

$-0.792^{* * *}$

$-0.396^{* * *}$

$(0.0669)$

(0.0663)

(0.0598)

$-0.685^{* * *}$

$-0.450 * * *$

$(0.0464)$

$(0.0420)$

$6.885^{* * *}$

$6.215^{* * *}$

(0.0574)

(0.0926)

No

Yes

10,365

10,365

10,387

0.037

0.233

Notes: Dependent variable is the environmental protection score (scale: $0-10$ ) of respondents. We report estimates from bivariate (Models 1 and 2) and multivariate regressions (Model 3), also controlling for party identification (Model 4). Robust standard errors are displayed in parentheses. ${ }^{*}\left(+,{ }^{* *}, * * *\right)$ indicates $p<0.05(0.1,0.01,0.001)$.

$66 \%$ of respondents do so, and without this display about 64\% (see Appendix Figure A.8). Figure 2 shows that this aggregate effect is driven by a specific subgroup: those in the combined heuristics and party-mean treatment condition (bottom row of Figure 2) who report not to know the candidate (left panel of Figure 2). ${ }^{14}$ Once we zoom in on these respondents, the baseline probability of placement is only around 50\% (rather than above 90\%), and it increases by 5.5 percentage points to about $55 \%$ (11\% of control group mean) when the party mean and ballot heuristics are shown. This is intuitive, since knowledge of the candidate per se will typically imply knowing his/her approximate age and possibly also where s/he lives. ${ }^{15}$ Overall, this implies that respondents who do not know the candidates gain additional confidence to locate them from the ballot heuristics, but only if they also receive basic information about the party position.

We now turn to $\mathrm{H} 2$ : how do respondents react to ballot heuristics when deciding where to place candidates on the environmental policy dimension? In particular, we investigate whether respondents place older or rural candidates lower on the environmental policy position scale, if this information is revealed to respondents. ${ }^{16}$ Figure 3 compares the placement of candidates by age group ("younger" vs. "older", left panel) and by residence ("urban" vs. "peri-urban" vs. "rural", right panel). Note that we are not interested in the differences across types of candidates per se (as we did not experimentally manipulate these types). What $\mathrm{H} 2$ does imply is that the placement of candidates shifts with the experimental revelation of ballot cues - the difference between older and younger (urban and more rural) candidates should become stronger when cues are provided [orange coefficients] compared to when they are not [green

\footnotetext{
${ }^{14}$ The difference also holds when pooling respondents over their knowledge of candidates (see Appendix Figure A.9).

${ }^{15}$ Importantly, the (reported) knowledge of the candidate itself is not affected by the treatments (as shown in Appendix Section A.4), so inference on this subgroup is valid.

${ }^{16}$ Note that, as expected, the mere revelation of any demographic information makes no difference for aggregate placement on the scale (see Appendix Figure A.10).
} 


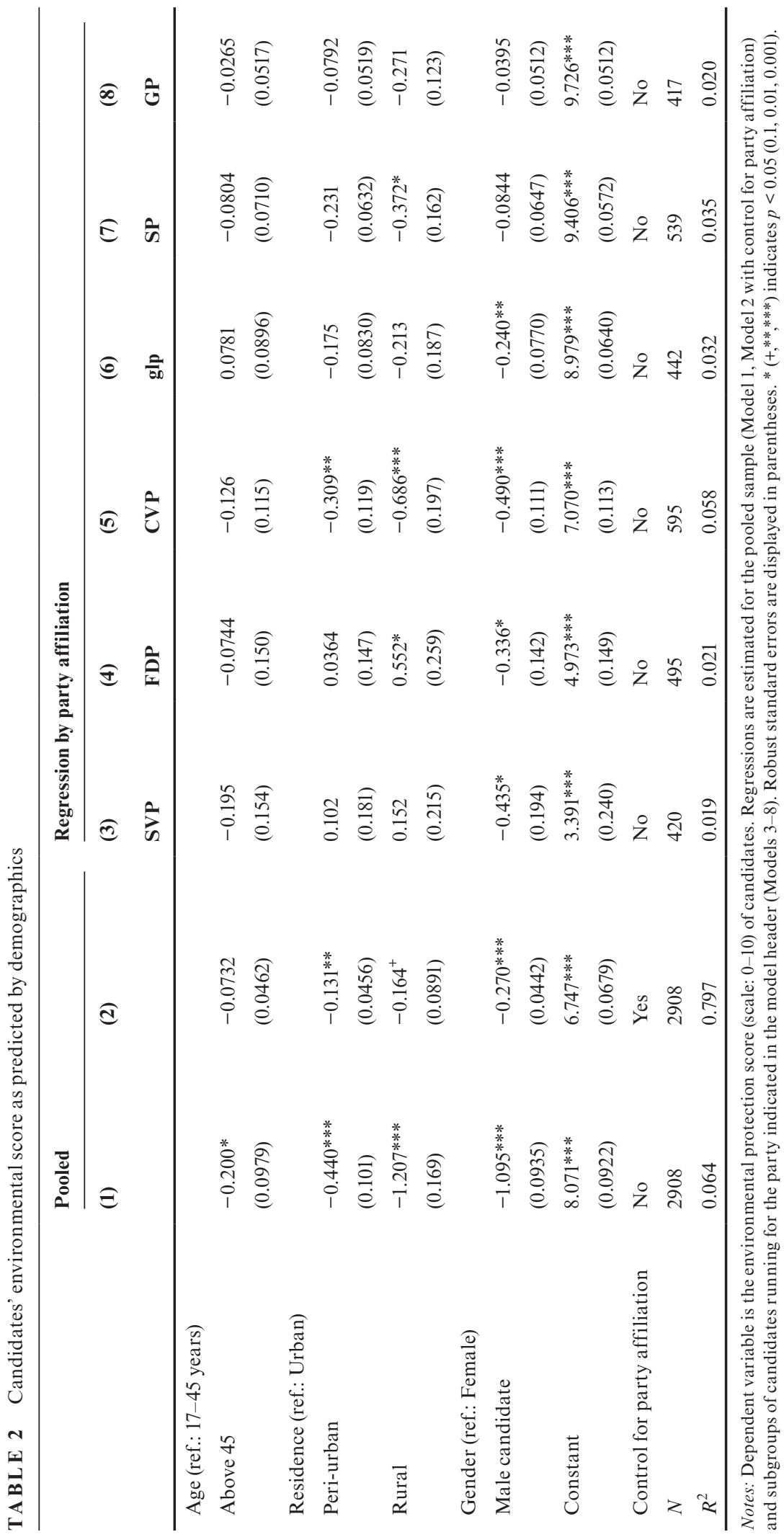




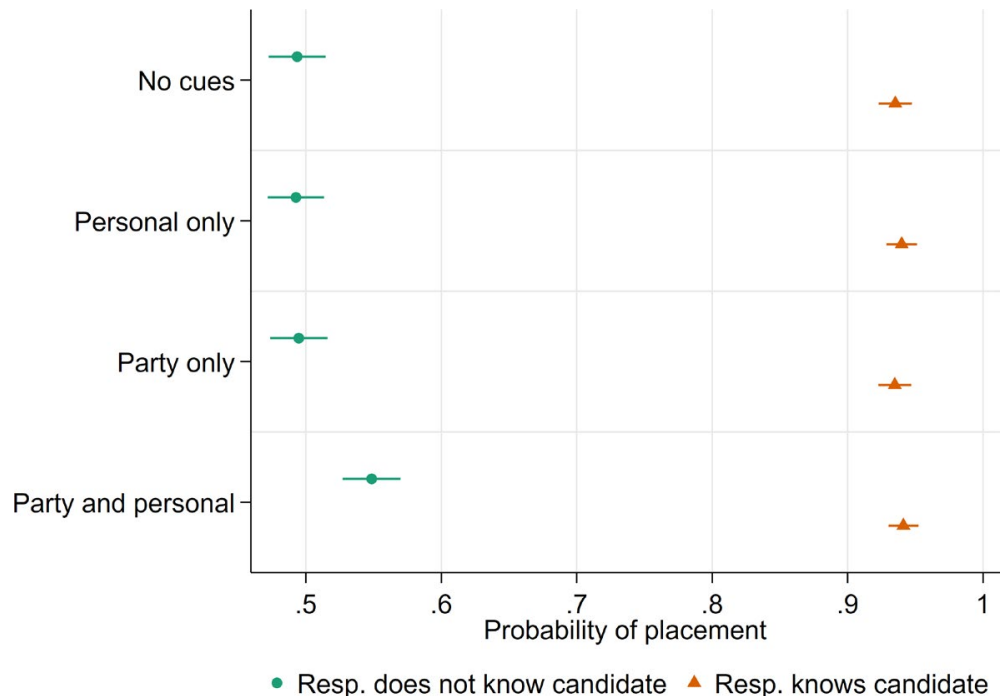

F I G U R E 2 Treatment increases probability of placement, but only in set of respondents without prior candidate knowledge.

Notes: Conditional means for a binary indicator whether respondent does not place a candidate (0) or does place (1) by four experimental conditions (0: control group, only candidate name and party affiliation displayed; 1 : name, party affiliation, age, residence displayed; 2 : name, party affiliation and party mean displayed; 3 : name, party affiliation, age, residence and party mean displayed) and by whether respondents state that they know or don't know the candidate. Sample is reduced to respondents who reply to the know/don't know the candidate question. 95\% confidence intervals from respondent-clustered standard errors are displayed. Appendix Table A.9 presents the corresponding regression coefficients (OLS and logit specifications). $N=28,770$; clusters $=9871$

coefficients]. In particular, with heuristics provided, younger (urban) candidates should receive higher/more pro-environmental scores, and older (rural) candidates lower ones. As can be seen, this is not the case. For younger versus older candidates, the gap actually widens slightly (by 0.12 scale points), though not significantly so, when cue treatments are displayed. For residence, we see no change in the corresponding gap for urban versus peri-urban candidates ( -0.01 scale points), and the gap for urban versus rural candidates also widens slightly but insignificantly (by 0.14 scale points). Taken together, we conclude that the revelation of ballot heuristics on age and residence does not affect where on the scale respondents place the candidates on average.

It could be asked whether the results change when we investigate the effects of the information cues on a party-by-party basis (see Figure 4). For H2, the effect is in the expected direction for age in the CVP (younger candidates are placed by 0.45 scale points closer to the green end than older candidates, with $p=0.17$ ). However, effects are in the opposite direction for the two environmentalist parties GP (coefficient of $-0.69, p=0.03$ ) and glp (coefficient of $-0.34, p=0.08$ ). Apparently, respondents perceive younger politicians in these parties as more moderate. For the information on residence, the revelation of a rural (as opposed to urban) origin causes the expected change to a less pro-environmental score for SP candidates $(-0.85, p=0.043)$, which corresponds to the pattern found for the candidates of the party in Table 2. When informed that SVP candidates live in the countryside, they are seen as more pro-environmental (by 0.55 scale points, $p=0.026$ ). The sign of this effect is also consistent with the patterns in politicians' positions reported in Table 2. For the other parties, and the peri-urban municipality category, we observe no significant shifts. Overall, the party-level analysis reinforces the conclusion that there is no strong or 

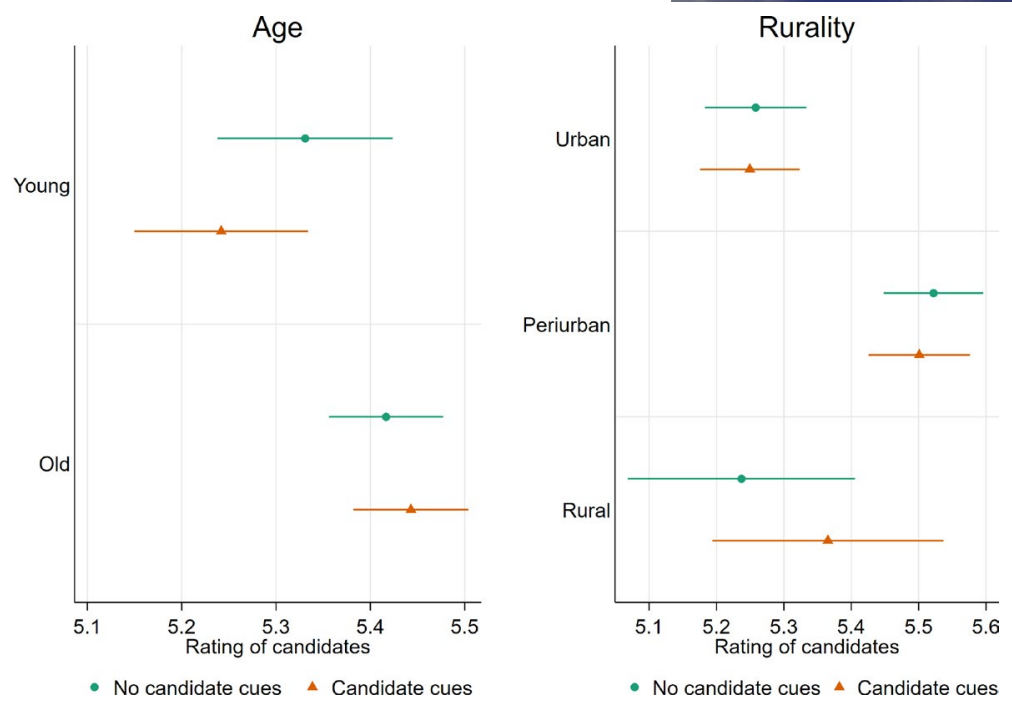

F I G U R E 3 Treatment (revelation of ballot cues on age or rurality) does not affect placement. Notes: Conditional means for a binary indicator on respondents' placement of young versus old candidates (left panel) and urban versus peri-urban versus rural candidates (right panel) on the 10-point environmental policy issue scale. Conditional means are depicted by two experimental conditions ( 0 : no ballot cues are revealed; 1 : age and residence of candidates are revealed). 95\% confidence intervals from respondent-clustered standard errors are displayed. Regression table presented in Appendix Table A.10. Left panel: $N=20,269$; clusters $=8032$. Right panel: $N=20,163 ;$ clusters $=8027$

consistent average usage of cues when citizens are asked to assess the environmental positions of candidates. ${ }^{17}$

Last, we turn to H3. Will citizens who are more interested in politics in general be more likely to use the candidate information cues? To examine this, we distinguish respondents stating high or very high political interest ( $29 \%$ of the sample) from those reporting at most medium political interest (71\%). We first assess this with regard to whether candidates are located at all (Figure 5). Unsurprisingly, respondents with high political interest have a higher probability of placing the candidate, irrespective of treatment. Exposure to the heuristics treatment increases the probability of an evaluation, but again only when also combined with the partymean treatment. There, it has a substantially large and significant effect (4.3 percentage points, $7 \%$ of control group mean) among respondents with low political interest (green coefficients) and a smaller and insignificant effect (1.2 percentage points, $1.5 \%$ of control group mean) with high political interest (orange coefficients).

Next, we turn to the average placement of candidates on the scale. As can be seen from Figure 6, respondents with high political interest are not more likely to use heuristics than less interested citizens. Those with high interest do not use the ballot cues in a particular way. Shifts in evaluations are - although mostly in the expected direction - minuscule. In contrast, among respondents with low political interest, the age cue is used but in the unexpected direction: when information is provided, low-interest respondents evaluate younger candidates as less "green" and older candidates as "greener". This difference is approximately a quarter of a scale point $(0.23, p=0.02)$. Appendix Figure A.15 shows that this age-effect in the low-interest group stems mainly from the placement of SVP, glp and GP candidates, where evaluations of older candidates are approximately half a

\footnotetext{
${ }^{17}$ In Appendix Section A.8, we show that this tendency of null-findings for H2 holds 1) when differentiating whether or not respondents state knowledge of the candidate, or 2) whether respondents are also exposed to the party-mean treatment, and 3) when respondents evaluate candidates for which both the age and residence cue go in the same direction (i.e., 'most likely'-cases to confirm H2).
} 

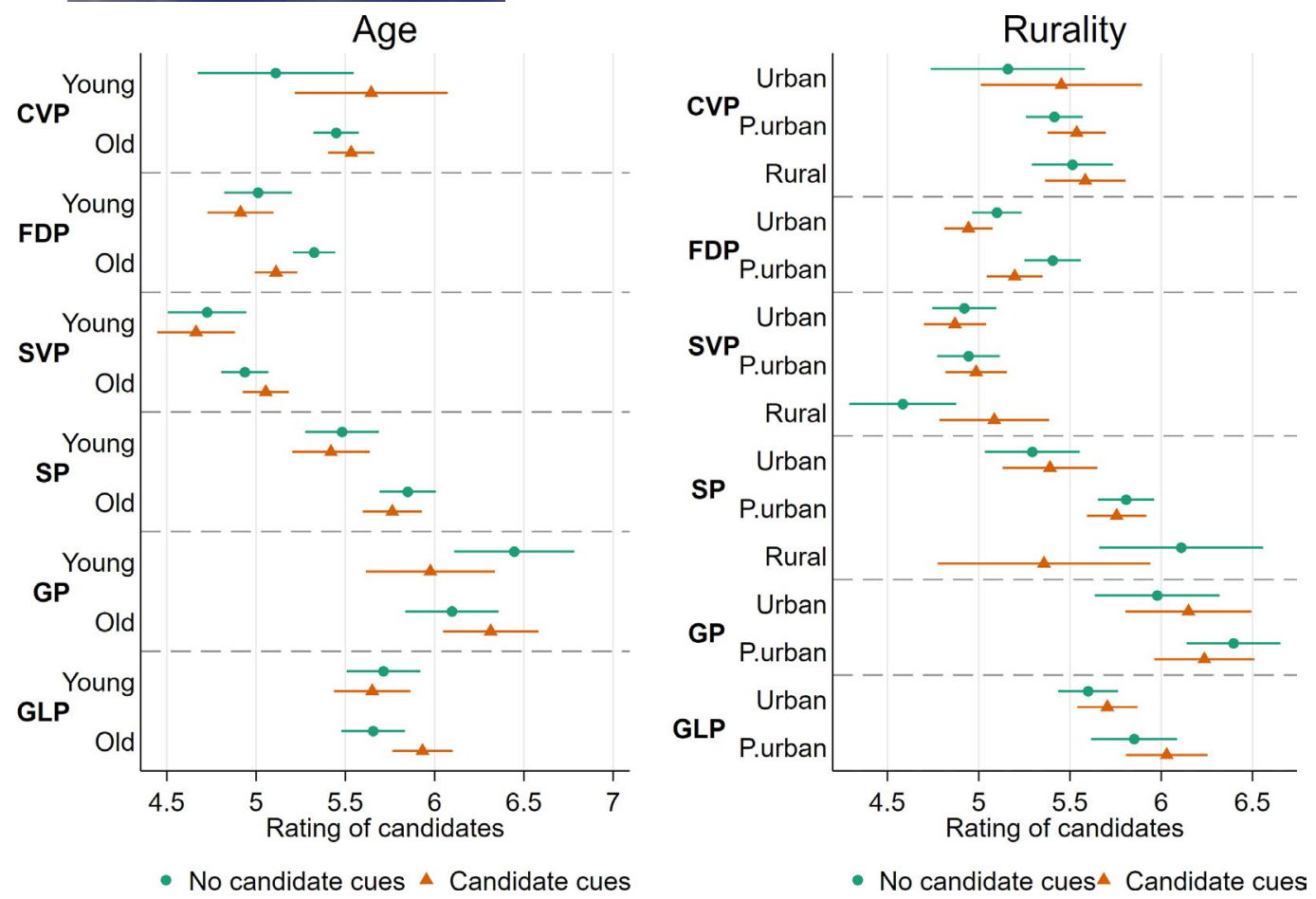

F I G U R E 4 Treatment (revelation of ballot cues on age or rurality) does not affect placement within party systematically.

Notes: Conditional means for a binary indicator on respondents' placement of young versus old candidates (left panel) and urban versus peri-urban versus rural candidates (right panel) on the 10-point environmental policy issue scale. Candidates are separated by the party they run for. Conditional means are depicted by two experimental conditions ( 0 : no ballot cues are revealed; 1 : age and residence of candidates are revealed). Parties FDP, GP and glp fielded no candidates from rural municipalities. 95\% confidence intervals from respondent-clustered standard errors are displayed. Appendix Table A.11 presents the corresponding regression coefficients. Left panel: $N=20,269$; clusters $=8032$. Right panel: $N=20,163$; clusters $=8027$

scale-point "greener" (significant at the 5\%-level) than those of younger candidates, under treatment. For residence (see Appendix Figure A.16), no statistically significant differences emerge between treatment groups (besides one shift for the SP in the expected direction in the high-interest group). Overall, we can therefore conclude that respondents with high political interest are not particularly likely to rely on ballot heuristics - if anything, it is respondents with low political interest who use these cues, but not as expected.

\section{Exploring an alternative explanation}

Taken together, we can conclude that respondents are more confident about expressing their opinion with the cue treatment. This is particularly so for respondents that do not know these candidates and that have low levels of political interest. The evidence is in line with Hypothesis 1. However, actual candidate placements do not shift meaningfully when ballot information is revealed. We therefore cannot find evidence in line with Hypotheses 2 and 3.

Why might this be the case? Perhaps the differences across age and residence groups in the wider population are simply too small for people to be noticed. Less sophisticated voters may not be aware of them, while more sophisticated perhaps are not either, or they are - in most cases rightly so - reluctant to use them when knowing the party affiliation of candidates. 


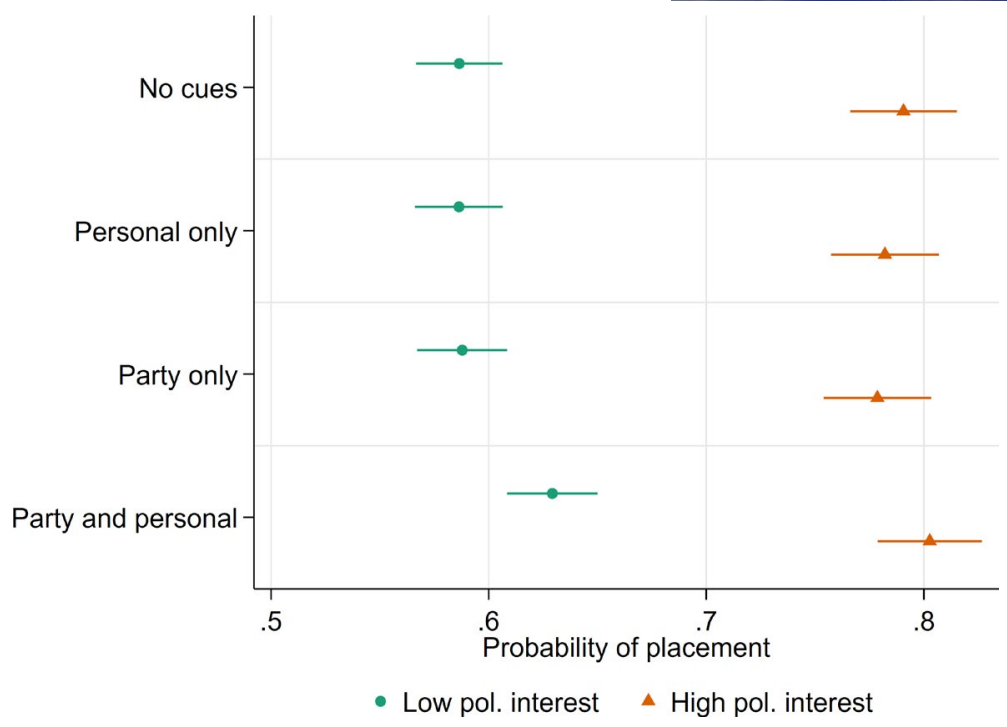

F I G UR E 5 Treatment increases probability of placement, but only if both party-mean and cue treatment are experimentally revealed, and more so with low political interest.

Notes: Conditional means for a binary indicator whether respondent does not evaluate a candidate (0) or does evaluate (1) by four experimental conditions ( 0 : control group; 1: age, residence displayed; 2: party mean displayed; 3: age, residence and party mean displayed) and by whether respondents state that they have low or high political interest. 95\% confidence intervals from respondent-clustered standard errors are displayed. Appendix Table A.12 presents the corresponding regression coefficients, from OLS and logit models. $N=28,739$; clusters $=9860$

Another possibility is that respondents might use the heuristics provided in an alternative fashion. It could be the case that respondents assess to what extent candidates resemble them (cp. Arnesen et al., 2019: 55). Respondents' placements of candidates could shift towards their own ideal points when candidates match their own personal characteristics. To check whether this is plausible, we conduct some additional exploratory analyses. We code a candidate as resembling a respondent when she is within an age band of 10 years and from a similar type of municipality (urban, peri-urban or rural municipality). Respondents are split into two groups, depending on whether their environmental ego-position is above or below the median.

Figure 7 shows predictions from the respective regression model. ${ }^{18}$ When a candidate does not resemble a respondent (left panel), the cues make no difference for the candidate placement on the scale (note that average ratings differ between more and less proenvironmental respondents). However, when a candidate matches a respondent in terms of demographics (right panel), "greener" respondents also rate these candidates as more pro-environmental, while the less "green" respondents assign lower/less proenvironmental scores once this information is experimentally revealed to them. Hence, both groups adjust the evaluation of matching candidates into the direction of their own environmental score when they are made aware of the resemblance. ${ }^{19}$ Overall, this points

\footnotetext{
${ }^{18}$ For full results, see Appendix Table A.5, Model 3. The main takeaway is the coefficient from the last row of the table: when 1) the respondent is "green", 2) the candidate matches the respondent's demographics, and 3) this is revealed to the respondent, the placement will shift towards the pro-environmental end of the scale.

${ }^{19}$ As presented in Appendix Table A.5, this difference is statistically significant at the $5 \%$-level and also holds when considering matches on merely one of the variables (Model 1, though statistically insignificant, and 2 of Appendix Table A.5). Effects become larger when respondents are also made aware of the party mean (cf. Appendix Table A.6) and when respondents report knowing the candidate (cf. Appendix Table A.7).
} 

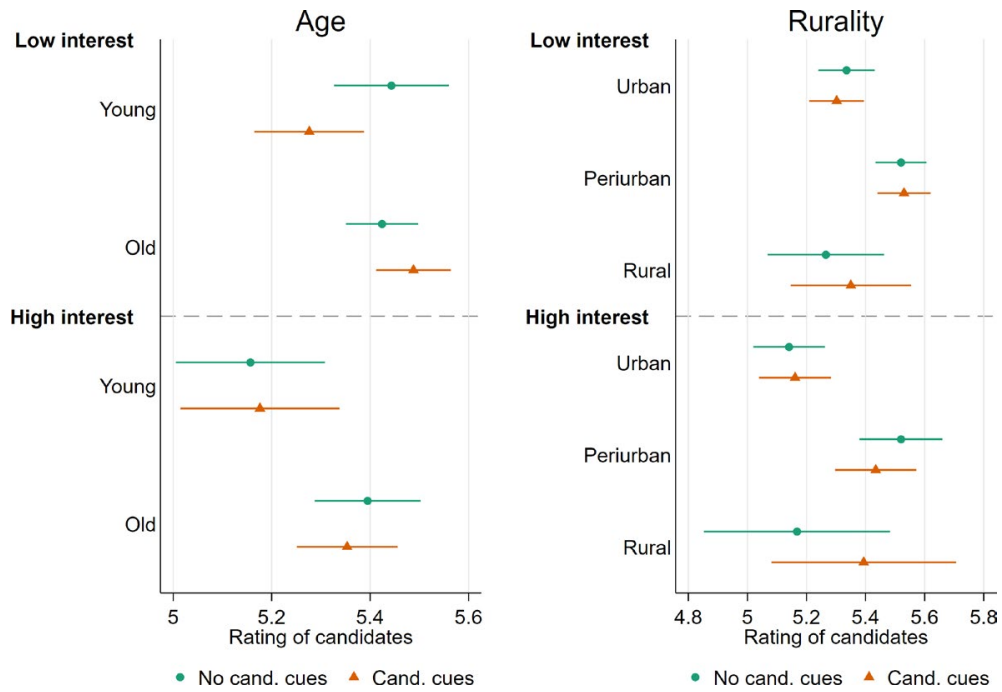

F I G U R E 6 Treatment has no specific effects within populations of high/low political interest.

Notes: Conditional means for a binary indicator on respondents' placement of young versus old candidates (left panel) and urban versus peri-urban versus rural candidates (right panel) on the 10-point environmental policy issue scale. Respondents are separated by (very) high versus (very) low or medium political interest. 95\% confidence intervals from robust standard errors are displayed. Appendix Table A.13 presents the corresponding regression coefficients. Left panel: $N=20,242$; clusters $=8022$. Right panel: $N=20,136$; clusters $=8017$

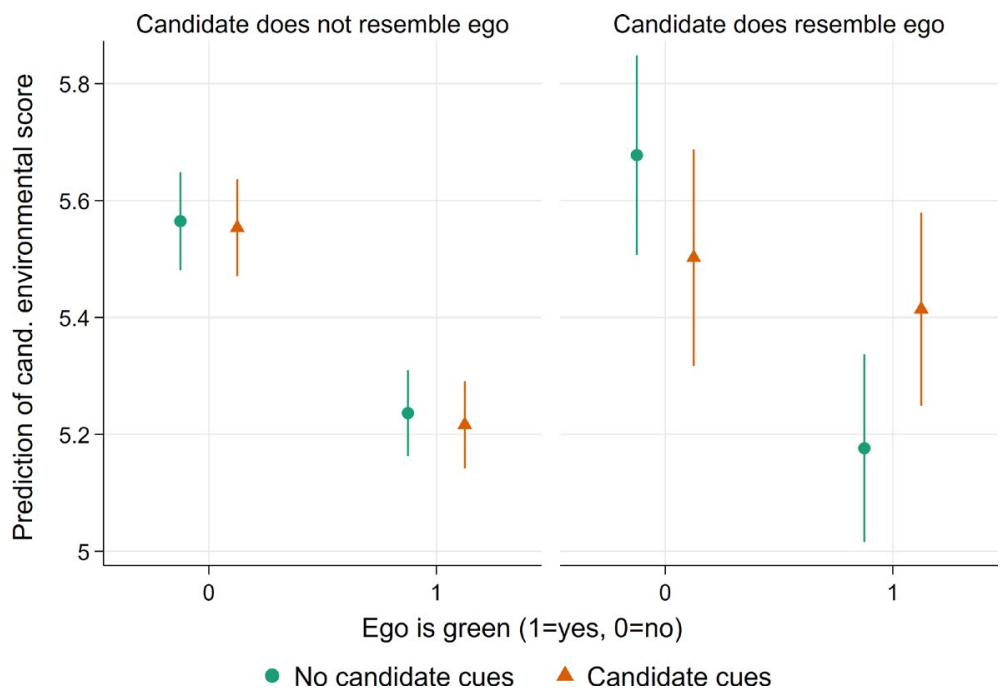

F I G U R E 7 Treatment induces respondents to place candidates that resemble them closer to their own policy view. Notes: Predicted candidate placement by whether a respondent is green (above median environmental score) or less green (below median environmental score), by whether the candidate to be placed differs on demographics to the respondent or resembles the respondent, and by treatment group (ballot information not provided vs. provided). $95 \%$ confidence intervals from respondent-level clustered standard errors are displayed. Appendix Table A.5 presents the corresponding regression coefficients (Model 3). $N=20,041$; clusters $=7969$

to projection as an alternative mechanism. Further research should investigate the robustness of this finding, also with more fine-grained measurement approaches and incorporating potential partisan effects. 


\section{CONCLUSION}

This paper asks whether sociodemographic characteristics of candidates can serve as cues to infer policy positions. In the context of list PR systems with intra-party choice, the question is particularly relevant for issues that are salient to the public, while dividing at least some of the parties internally. These systems provide incentives for parties to field candidates with heterogeneous positions (Matakos et al., 2018; Tromborg, 2021), and experiments reveal that citizens take into account information about candidate positions when directly provided (Blumenau et al., 2017; Bräuninger et al., 2021). In practice, though, voters may not be very well-informed. Ballot-level cues could provide a means to overcome this problem.

The Swiss election campaign of 2019 was characterized by a strong focus on environmental topics, on which several parties are internally divided. Despite the prominence of environmental issues, citizens' knowledge about candidates' positions in this policy field was very limited. At the same time, we could not find evidence that Swiss citizens use candidate age or residence as direct predictors for where politicians stand with regard to environmental protection. Associations between age or residence and environmental attitudes turn out to be fairly small in the wider population, and they differentiate candidates only within some parties. Hence, heuristics that younger or city-based candidates are "greener" would quite often have been misleading anyway.

While the title question of this paper receives a negative answer for environmental policy in the Swiss 2019 elections, this need not be the case in other contexts. It is conceivable that associations between sociodemographic variables and attitudes among the population, where more pronounced, do translate into the use of corresponding heuristics. Whether sociodemographics may be and are used as predictors can therefore not be answered in a general fashion. Similar studies could therefore consider the role of socio-economic background for issues linked to redistribution, or of age and gender for socio-cultural issues, since these variables have been shown to explain variation in respective policy positions within Swiss parties (Kissau et al., 2012; Lloren \& Rosset, 2017; Lloren et al., 2015). How the usage of cues differs across parties, depending on, for example, issue salience or perceptions of intra-party heterogeneity, is also a promising avenue.

Our initial evidence that citizens' placements are affected by self-resemblance points to another worthwhile avenue for further research. While a good deal is known about projection effects in placements of liked and disliked parties (e.g., Grand \& Tiemann, 2013; Ward \& Tavits, 2019), there is little work on the perception of candidate positions in list PR systems. This gap should be addressed, also because it is linked to important questions regarding the relationship between descriptive and substantive representation (Arnesen et al., 2019).

\section{ACKNOWLEDGMENTS}

We are grateful to Michael Erne and Daniel Schwarz (Smartvote) for providing data on candidates and their issue positions. We also thank Janek Bruker, Colin Walder and Nick Radowsky for their excellent research assistance, and participants of the 2021 ECPR Joint Sessions Workshop on "Intraparty Competition in Comparative Perspective" for helpful feedback. Open access funding provided by Eidgenossische Technische Hochschule Zurich.

\section{DATA AVAILABILITY STATEMENT}

Data and code to replicate all respondent-level analyses are available at Harvard Dataverse under https://doi.org/10.7910/DVN/YLNSOK. The candidate-level analyses rely on data provided by Smartvote (2019b) which was provided to the authors under an agreement not to make these publicly available. These data can be requested from Smartvote directly, and code to reproduce this analysis is available from the authors upon request. 


\section{ORCID}

Thomas Däubler (D) https://orcid.org/0000-0001-5106-4918

Franziska Quoß (D) https://orcid.org/0000-0001-9549-2922

Lukas Rudolph (D) https://orcid.org/0000-0001-8977-4480

\section{REFERENCES}

Arnesen, S., Duell, D., \& Johannesson, M. P. (2019). Do citizens make inferences from political candidate characteristics when aiming for substantive representation? Electoral Studies, 57, 46-60. https://doi.org/10.1016/j.elect stud.2018.10.005

Arter, D. (2014). Clowns, 'alluring ducks' and 'miss Finland 2009': The value of 'celebrity candidates' in an open-list PR voting system. Representation, 50(4), 453-470. https://doi.org/10.1080/00344893.2014.982693

Banducci, S., Giebler, H., \& Kritzinger, S. (2017). Knowing more from less: How the information environment increases knowledge of party positions. British Journal of Political Science, 47(3), 571-588. https://doi.org/10.1017/ S0007123415000204

Bernhard, L. (2020). The 2019 Swiss federal elections: The rise of the green tide. West European Politics, 43(6), 13391349. https://doi.org/10.1080/01402382.2019.1710687

Blom-Hansen, J., Elklit, J., Serritzlew, S., \& Villadsen, L. R. (2016). Ballot position and election results: Evidence from a natural experiment. Electoral Studies, 44, 172-183. https://doi.org/10.1016/j.electstud.2016.06.019

Blumenau, J., Eggers, A. C., Hangartner, D., \& Hix, S. (2017). Open/closed list and party choice: Experimental evidence from the UK. British Journal of Political Science, 47(4), 809-827. https://doi.org/10.1017/S0007123415000629

Bowler, S., \& Nicholson, S. P. (2018). Information cues and rational ignorance. In R. D. Congleton, B. Grofman, \& S. Voigt (Eds.), The Oxford handbook of public choice (pp. 381-394). Oxford University Press.

Bräuninger, T., Däubler, T., Huber, R. A., \& Rudolph, L. (2021). How open lists undermine the electoral support of cohesive parties. British Journal of Political Science, forthcoming. https://doi.org/10.1017/S0007123421000417

Brockington, D. (2003). A low information theory of ballot position effect. Political Behavior, 25(1), 1-27.

Bühlmann, M., Zumbach, D., Gerber, M., \& Heidelberger, A. (2016). Cherry picking at the 2015 Swiss Federal Elections: The influence of electoral campaigning on panachage and cumulation. Conference manuscript, 10th ECPR General Conference, Prague.

Buttel, F. H. (1992). Environmentalization: Origins, processes, and implications for rural social change. Rural Sociology, 57(1), 1-27.

Carmines, E. G., \& Layman, G. C. (1997). Value priorities, partisanship and electoral choice: The neglected case of the United States. Political Behavior, 19(4), 283-316.

Carnes, N., \& Sadin, M. L. (2015). The "Mill Worker's Son" heuristic: How voters perceive politicians from working-class families - And how they really behave in office. The Journal of Politics, 77(1), 285-298. https://doi.org/10.1086/678530

Coffé, H., \& von Schoultz, Å. (2020). How candidate characteristics matter: Candidate profiles, political sophistication, and vote choice. Politics, 41(2), 137-155. https://doi.org/10.1177/0263395720922077

Conover, P. J., \& Feldman, S. (1989). Candidate perception in an ambiguous world: Campaigns, cues, and inference processes. American Journal of Political Science, 33(4), 912-940. https://doi.org/10.2307/2111115

Dahlberg, S., \& Harteveld, E. (2016). Left-right ideology as an inferential device in multiparty systems: Can citizens overcome low information by imputing parties' policy positions? Electoral Studies, 42, 175-187. https://doi. org/10.1016/j.electstud.2016.02.016

Dahlgaard, J. O. (2016). You just made it: Individual incumbency advantage under proportional representation. Electoral Studies, 44, 319-328. https://doi.org/10.1016/j.electstud.2016.09.004

Dancey, L., \& Sheagley, G. (2013). Heuristics behaving badly: Party cues and voter knowledge. American Journal of Political Science, 57(2), 312-325. https://doi.org/10.1111/j.1540-5907.2012.00621.x

Däubler, T., \& Rudolph, L. (2020). Cue-Taking, satisficing, or both? Quasi-experimental evidence for ballot position effects. Political Behavior, 42(2), 625-652. https://doi.org/10.1007/s11109-018-9513-1

Devroe, R., \& Wauters, B. (2018). Political gender stereotypes in a list-PR system with a high share of women MPs: Competent men versus leftist women? Political Research Quarterly, 71(4), 788-800. https://doi.org/10.1177/10659 12918761009

Echavarren, J. M. (2017). From objective environmental problems to subjective environmental concern: A multilevel analysis using 30 indicators of environmental quality. Society \& Natural Resources, 30(2), 145-159. https://doi. org/10.1080/08941920.2016.1185555

Egan, P. J., \& Mullin, M. (2017). Climate change: US public opinion. Annual Review of Political Science, 20, $209-227$. https://doi.org/10.1146/annurev-polisci-051215-022857

Faas, T., \& Schoen, H. (2006). The importance of being first: Effects of candidates' list positions in the 2003 Bavarian state election. Electoral Studies, 25(1), 91-102. https://doi.org/10.1016/j.electstud.2005.04.001

Federal Office for Spatial Development. (2017). Bauzonenstatistik Schweiz. https://www.are.admin.ch/are/de/home/ raumentwicklung-und-raumplanung/grundlagen-und-daten/bauzonenstatistik-schweiz.html 
Fivaz, J., \& Nadig, G. (2010). Impact of voting advice applications (VAAs) on voter turnout and their potential use for civic education. Policy \& Internet, 2(4), 167-200. https://doi.org/10.2202/1944-2866.1025

Fortunato, D., \& Stevenson, R. T. (2019). Heuristics in context. Political Science Research and Methods, 7(2), 311-330. https://doi.org/10.1017/psrm.2016.37

Franzen, A., \& Meyer, R. (2010). Environmental attitudes in cross-national perspective: A multilevel analysis of the ISSP 1993 and 2000. European Sociological Review, 26(2), 219-234. https://doi.org/10.1093/esr/jcp018

Franzen, A., \& Vogl, D. (2013). Two decades of measuring environmental attitudes: A comparative analysis of 33 countries. Global Environmental Change, 23(5), 1001-1008. https://doi.org/10.1016/j.gloenvcha.2013.03.009

Gigerenzer, G., \& Gaissmaier, W. (2011). Heuristic decision making. Annual Review of Psychology, 62, 451-482. https://doi.org/10.1146/annurev-psych-120709-145346

Grand, P., \& Tiemann, G. (2013). Projection effects and specification bias in spatial models of European Parliament elections. European Union Politics, 14(4), 497-521. https://doi.org/10.1177/1465116513490238

Hehli, S. \& Thelitz, N. (2019). Totaler Umweltschutz, kein Rentenalter 67, Cannabis-Freigabe - so schlägt sich der grüne Triumph im Nationalrat nieder. Neue Zürcher Zeitung. https://www.nzz.ch/schweiz/ wahlen-2019-so-tickt-das-neue-parlament-ld.1516802

Heinsohn, T., Fatke, M., Israel, J., Marschall, S., \& Schultze, M. (2019). Effects of voting advice applications during election campaigns. Evidence from a panel study at the 2014 European elections. Journal of Information Technology \& Politics, 16(3), 250-264. https://doi.org/10.1080/19331681.2019.1644265.

Hilton, J. L., \& Von Hippel, W. (1996). Stereotypes. Annual Review of Psychology, 47(1), 237-271. https://doi. org/10.1146/annurev.psych.47.1.237

Huddy, L., \& Terkildsen, N. (1993). Gender stereotypes and the perception of male and female candidates. American Journal of Political Science, 37(1), 119-147. https://doi.org/10.2307/2111526

Humbel, G. (2021). Die Millionenschlacht um die Zukunft der Landwirtschaft. SRF News. https://www.srf.ch/news/ schweiz/agrarinitiativen-die-millionenschlacht-um-die-zukunft-der-landwirtschaft

Inglehart, R. (1995). Public support for environmental protection: Objective problems and subjective values in 43 societies. PS: Political Science and Politics, 28(1), 57-72.

Kissau, K., Lutz, G., \& Rosset, J. (2012). Unequal representation of age groups in Switzerland. Representation, 48(1), 63-81. https://doi.org/10.1080/00344893.2012.653241

Koch, J. W. (2000). Do citizens apply gender stereotypes to infer candidates' ideological orientations? The Journal of Politics, 62(2), 414-429. https://doi.org/10.1111/0022-3816.00019

Kurella, A.-S., \& Rosset, J. (2018). The rise of cultural issues as an opportunity for the right? Insights from the 2015 Swiss election. Swiss Political Science Review, 24(4), 381-399. https://doi.org/10.1111/spsr.12327

Ladner, A., Fivaz, J., \& Pianzola, J. (2012). Voting advice applications and party choice: Evidence from Smartvote users in Switzerland. International Journal of Electronic Governance, 5(3-4), 367-387. https://doi.org/10.1504/ IJEG.2012.051303

Liere, K. D. V., \& Dunlap, R. E. (1980). The social bases of environmental concern: A review of hypotheses, explanations and empirical evidence. Public Opinion Quarterly, 44(2), 181-197. https://doi.org/10.1086/268583

Lloren, A., \& Rosset, J. (2017). Gendered policy preferences? Candidates' views on political issues in a comparative perspective. Comparative European Politics, 15(6), 944-968. https://doi.org/10.1057/cep.2015.4

Lloren, A., Rosset, J., \& Wüest, R. (2015). Descriptive and substantive representation of poor citizens in Switzerland. Swiss Political Science Review, 21(2), 254-260. https://doi.org/10.1111/spsr.12159

Lupia, A., \& McCubbins, M. D. (1998). The democratic dilemma - Can citizens learn what they need to know? Cambridge University Press.

Lutz, G. (2010). First come, first served: The effect of ballot position on electoral success in open ballot PR elections. Representation, 46(2), 167-181. https://doi.org/10.1080/00344893.2010.485808

Matakos, K., Savolainen, R., Troumpounis, O., Tukiainen, J., \& Xefteris, D. (2018). Electoral institutions and intraparty cohesion. VATT Institute for Economic Research Working Papers 109. https://doi.org/10.2139/ssrn.3212638

McDermott, M. L. (1997). Voting cues in low-information elections: Candidate gender as a social information variable in contemporary United States elections. American Journal of Political Science, 41(1), 270-283. https://doi. org/10.2307/2111716

McDermott, M. L. (1998). Race and gender cues in low-information elections. Political Research Quarterly, 51(4), 895-918. https://doi.org/10.1177/106591299805100403

McGarty, C., Yzerbyt, V. Y., \& Spears, R. (2002). Social, cultural and cognitive factors in stereotype formation. In C. McGarty, V. Y. Yzerbyt, \& R. Spears (Eds.), Stereotypes as explanations: The formation of meaningful beliefs about social groups (pp. 1-16). Cambridge University Press.

McMillan, M. B., Hoban, T. J., Clifford, W. B., \& Brant, M. R. (1997). Social and demographic influences on environmental attitudes. Journal of Rural Social Sciences, 13(1), 5.

Mohai, P., \& Twight, B. W. (1987). Age and environmentalism: An elaboration of the Buttel model using national survey evidence. Social Science Quarterly, 68(4), 798.

Munzert, S., Barberá, P., Guess, A., \& Yang, J. H. (2020). Do online voter guides empower citizens? Evidence from a field experiment with digital trace data. Public Opinion Quarterly, 84(3), 675-698. https://doi.org/10.1093/poq/nfaa037 
Mustillo, T., \& Polga-Hecimovich, J. (2020). Party, candidate, and voter incentives under free list proportional representation. Journal of Theoretical Politics, 32(1), 143-167. https://doi.org/10.1177/0951629819893023

Pedersen, R. T., Dahlgaard, J. O., \& Citi, M. (2019). Voter reactions to candidate background characteristics depend on candidate policy positions. Electoral Studies, 61. https://doi.org/10.1016/j.electstud.2019.102066

Poortinga, W., Whitmarsh, L., Steg, L., Böhm, G., \& Fisher, S. (2019). Climate change perceptions and their individual-level determinants: A cross-European analysis. Global Environmental Change, 55, 25-35. https://doi. org/10.1016/j.gloenvcha.2019.01.007

Popkin, S. L. (1991). The reasoning voter: Communication and persuasion in presidential campaigns. University of Chicago Press.

Popkin, S., Gorman, J. W., Phillips, C., \& Smith, J. A. (1976). Comment: What have you done for me lately? Toward an investment theory of voting. American Political Science Review, 70(3), 779-805. https://doi.org/10.1017/S0003 055400174246

Redlawsk, D. P., \& Lau, R. R. (2013). Behavioral decision-making. In L. Huddy, D. O. Sears, \& J. S. Levy (Eds.), The Oxford handbook of political psychology (2nd ed., pp. 130-164). Oxford University Press.

Rudolph, L., Quoß, F., Wehrli, S., \& Bernauer, T. (2021). Swiss Environmental Panel Study 2018-2020, Wave 1-6, Cumulative Data [Dataset]. ETH Zurich - Institute of Science, Technology and Policy. Distributed by FORS, Lausanne, 2021. https://doi.org/10.23662/FORS-DS-1220-2

Schultze, M. (2014). Effects of voting advice applications (VAAs) on political knowledge about party positions. Policy \& Internet, 6(1), 46-68. https://doi.org/10.1002/1944-2866.POI352

Selb, P., \& Lutz, G. (2015). Lone fighters: Intraparty competition, interparty competition, and candidates' vote seeking efforts in open-ballot PR elections. Electoral Studies, 39, 329-337. https://doi.org/10.1016/j.elect stud.2014.04.009

Shugart, M. S., Valdini, M. E., \& Suominen, K. (2005). Looking for locals: Voter information demands and personal vote-earning attributes of legislators under proportional representation. American Journal of Political Science, 49(2), 437-449. https://doi.org/10.1111/j.0092-5853.2005.00133.x

Smartvote. (2019a). Council of States elections on 20.10.2019. Smartvote. https://smartvote.ch/en/group/2/elect ion/19chsr/home

Smartvote. (2019b). Daten der Online-Wahlhilfe smartvote.ch zu den Eidg. Wahlen 2019. www.smartvote.ch

Smartvote. (2019c). National Council Elections on 20.10.2019. Smartvote. https://smartvote.ch/en/group/2/elect ion/19_ch_nr/home

SRF. (2019). Das war die «Klimawahl»-Das Protokoll zum Nachlesen. SRF news. https://www.srf.ch/news/schwe iz/wahlen-2019/gruene-neu-viertstaerkste-kraft-das-war-die-klimawahl-das-protokoll-zum-nachlesen

Tromborg, M. W. (2021). Appealing broadly while appearing unified: Resolving an electoral dilemma. European Journal of Political Research, 60(1), 131-152. https://doi.org/10.1111/1475-6765.12393

von Schoultz, Å., \& Papageorgiou, A. (2019). Policy or person? The electoral value of policy positions and personal attributes in the Finnish open-list system. Party Politics, 27(4), 767-778. https://doi.org/10.1177/1354068819 891048

Ward, D. G., \& Tavits, M. (2019). How partisan affect shapes citizens' perception of the political world. Electoral Studies, 60, 102045. https://doi.org/10.1016/j.electstud.2019.04.009

\section{AUTHOR BIOGRAPHIES}

Thomas Däubler is Assistant Professor and Ad Astra Fellow at University College Dublin. His research focuses on electoral systems, legislative politics, and political parties.

Franziska Quoß is a $\mathrm{PhD}$ candidate at ETH Zurich. Her research interests are environmental attitudes, the interplay between the environmental and political system and survey methodology.

Lukas Rudolph is Senior Research Fellow at LMU Munich and Research Associate at ETH Zurich. His research covers questions of political behavior, preference formation, and the role of electoral institutions, with a specific interest in environmental politics and a methodological focus on survey experiments and causal inference. 


\section{SUPPORTING INFORMATION}

Additional supporting information may be found in the online version of the article at the publisher's website.

How to cite this article: Däubler, T., Quoß, F., \& Rudolph, L. (2021). Do Citizens use Sociodemographic Characteristics as Cues to Infer Candidate Issue Positions? Swiss Political Science Review, 00, 1-23. https://doi.org/10.1111/spsr.12493 


\section{Online Appendix for \\ 'Do citizens use sociodemographic characteristics as cues to infer candidate issue positions?'}

T. Däubler, F. Quoß and L. Rudolph

2021-09-16

Forthcoming in Swiss Political Science Review

\section{A.1 Description of the survey items, sample and relation be- tween age and environmental score}

Respondents were asked about their party identification (PID) using the following question: "In general, which political party best represents your opinions? Please name one party, even if you are not eligible to vote.".

We measure political interest with the following survey item: "How strongly or not strongly are you interested in politics in general?". Respondents could answer on a scale from 1 (not strongly at all) to 5 (very strongly). For the binary measure of political interest, everything from 1-3 (not strongly at all, not strongly, medium) is coded as 0, and 4-5 (strongly, very strongly) as 1. 
Table A.1: Descriptive statistics

\begin{tabular}{lccccc}
\hline \hline & & 5 & & & \\
& & & & & \\
& mean & sd & $\min$ & $\max$ & count \\
\hline Resp. environmental score & 5.96 & 2.41 & 0 & 10 & 10401 \\
Age $>$ 45 yrs & 0.62 & 0.49 & 0 & 1 & 10677 \\
Municipality type==Urban & 0.25 & 0.43 & 0 & 1 & 10743 \\
Municipality type==Periurban & 0.51 & 0.50 & 0 & 1 & 10743 \\
Municipality type==Rural & 0.24 & 0.43 & 0 & 1 & 10743 \\
Gender $==$ male & 0.50 & 0.50 & 0 & 1 & 10685 \\
PID $==$ CVP & 0.075 & 0.26 & 0 & 1 & 10758 \\
PID $==$ FDP & 0.13 & 0.33 & 0 & 1 & 10758 \\
PID $==$ SVP & 0.16 & 0.37 & 0 & 1 & 10758 \\
PID $==$ SP & 0.15 & 0.36 & 0 & 1 & 10758 \\
PID $==$ GP & 0.095 & 0.29 & 0 & 1 & 10758 \\
PID $==$ glp & 0.10 & 0.30 & 0 & 1 & 10758 \\
PID $==$ Other $/$ missing & 0.29 & 0.45 & 0 & 1 & 10758 \\
\hline $\mathrm{N}$ & 10758 & & & & \\
\hline \hline
\end{tabular}

Descriptive statistics of survey respondent characteristics. 


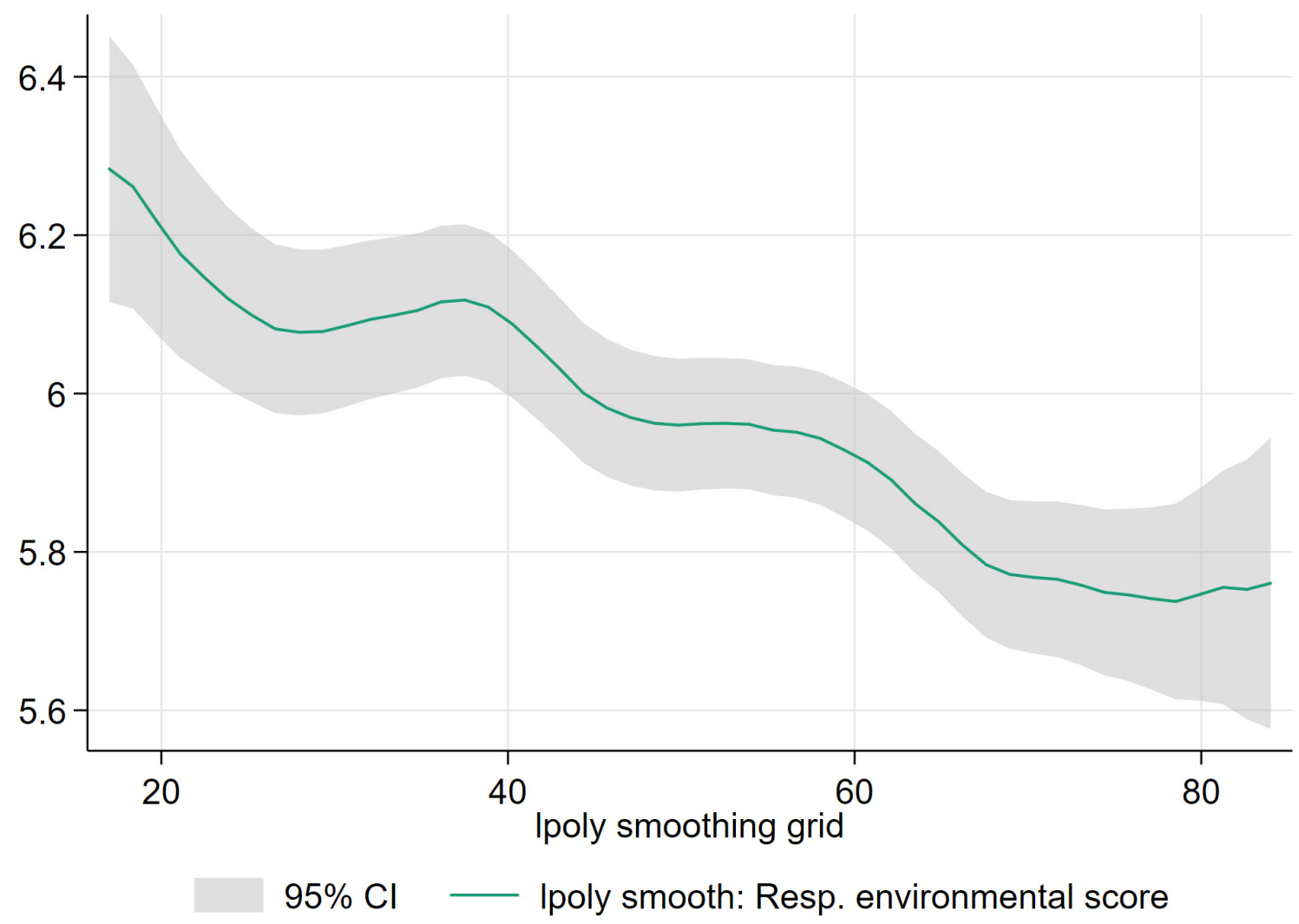

Figure A.1: Kernel-weighted local polynomial smooth plot of environmental score on age with local mean smoothing and $95 \%$ confidence interval. Age restricted to range $17-85$. 


\section{A.2 Definition of candidate set}

We describe the selection of candidates that were displayed to study participants. Respondents always saw a selection of real candidates from their respective canton, so the selection procedure described here takes place on the level of canton. We first designed a general set, from which we then drew a random subset that is to be displayed. The set is defined as follows: First of all, we focused on party representatives of the six largest Swiss parties (as represented in national parliament), i.e. candidates from the SVP, SP, CVP, FDP, glp, and GPS. This allows us to make party-level comparisons across all respondents. Among these, we presume that respondents have, if at all, a hunch of the position of visible candidates. We therefore exclude backbenchers and second-row candidates, and focus on those that are party frontrunners in the Ständerats-election (second chamber) (one candidate per party) and among the list leaders (top 3 positioned candidates of main party list) in the concurrent Nationalrats-election (first chamber). Additionally, if they compete in the elections, we take current incumbents into our candidate set, irrespective of their list position. Among this set, we distinguish candidates that we deem more or less difficult to position. As 'easy' candidates, we define those within one scale point of the party median. As 'difficult' candidates we define those more than one scale point away from their party median. A random draw of this 'difficult' set of candidates we display to respondents. Among the 'easy' candidates, we displayed one each from the set of parties SP, GP and glp ('green party block'), and one from the set of parties CVP, FDP and SVP ('non-green party block') (we therefore block the randomized display by party group). This is, as among SP, GP and glp the majority of candidates is very pro-environment on average, clusters closely around the respective party means, and the mean party position of these three parties is close to each other at the right end of the scale. Among CVP, FDP and SVP, candidates are rather heterogeneous and party means diverge.

We then made a block-random draw within canton and the three types ('difficult candidate', 'easy candidate from green party block', 'easy candidate from non-green party block'). Note that as we wanted to display three candidates for each and every respondent, we had to fill up otherwise empty spots in a few cases (small cantons where no 'difficult'

Table A.2: Environmental Score of Candidates by Party

\begin{tabular}{l|l|l}
\hline Party & Mean Env. Score & sd \\
\hline CVP & 64.55 & 14.25 \\
\hline FDP & 47.95 & 15.50 \\
\hline SVP & 30.64 & 16.01 \\
\hline SP & 91.85 & 7.61 \\
\hline GP & 96.34 & 5.26 \\
\hline glp & 87.66 & 8.58 \\
\hline BDP & 65.54 & 13.01 \\
\hline
\end{tabular}




\begin{tabular}{|l|l|l|}
\hline Threshold & Candidate reported as known & Candidate reported as not known \\
\hline+-1 & $21.3 \%$ & $20.1 \%$ \\
\hline+-2 & $40.5 \%$ & $38.6 \%$ \\
\hline
\end{tabular}

Table A.3: Share of respondents correctly assessing candidate positions

candidate was running or where one of the party blocks had no running candidate).

To summarize, the candidate set we can make inference for is defined as set of frontrunner and incumbent candidates from the six large and nation-wide competing Swiss parties, with randomized selection of displayed candidates from this set blocked by green vs. non-green party block among candidates with proximate environmental issue position relative to their party mean and candidates with larger distance to the environmental issue position of their party mean.

\section{A.3 Knowledge of candidates and ability to assess their envi- ronmental positions}

We focus on a subset of candidates that are most likely to be visible. Even with this set of quite visible candidates, only $33.7 \%$ of the answers (i.e. respondent-candidate pairs; some respondents did not evaluate all three candidates) in the control group state that the candidate as such was known to them.

While overall levels of self-stated knowledge of the candidates are thus low, we also assess whether respondents are able to correctly place the candidates on the environmental dimension. To do so, we compare the answers with the true (Smartvote) score of the candidate on the 11-point environmental scale. In this context, we use two different thresholds for determining what counts as "correctly evaluating the candidate". The stricter threshold requires the answer to fall in the range of +-1 points of the true score, a more generous rule uses a window of +-2 points. As Table A.3 shows, even with the generous two-point threshold, considerably less than half of the answers in the control group would be considered as correct. Secondly, the share of correct assessments is only marginally larger than the proportion expected if respondents simply guessed by placing candidates randomly on the 0-10 scale. Lastly, whether or not the candidate is (reported as) known makes almost no difference.

\section{A.4 Knowledge of candidate depending on treatment}

Central for estimating effects for subgroups of candidate knowledge is that the treatment itself does not affect respondents judgement whether they know a candidate. Hence, to exclude the possibility that providing treatment information on age and residence leads to higher stated recognition levels, we test this association explicitly. As can be seen from 
Figure A.2 such an association is unlikely to be the case. Irrespective of treatment condition, around a third of respondent state knowing a candidate. Importantly, differences between treatment conditions are substantially very small and statistically insignificant.

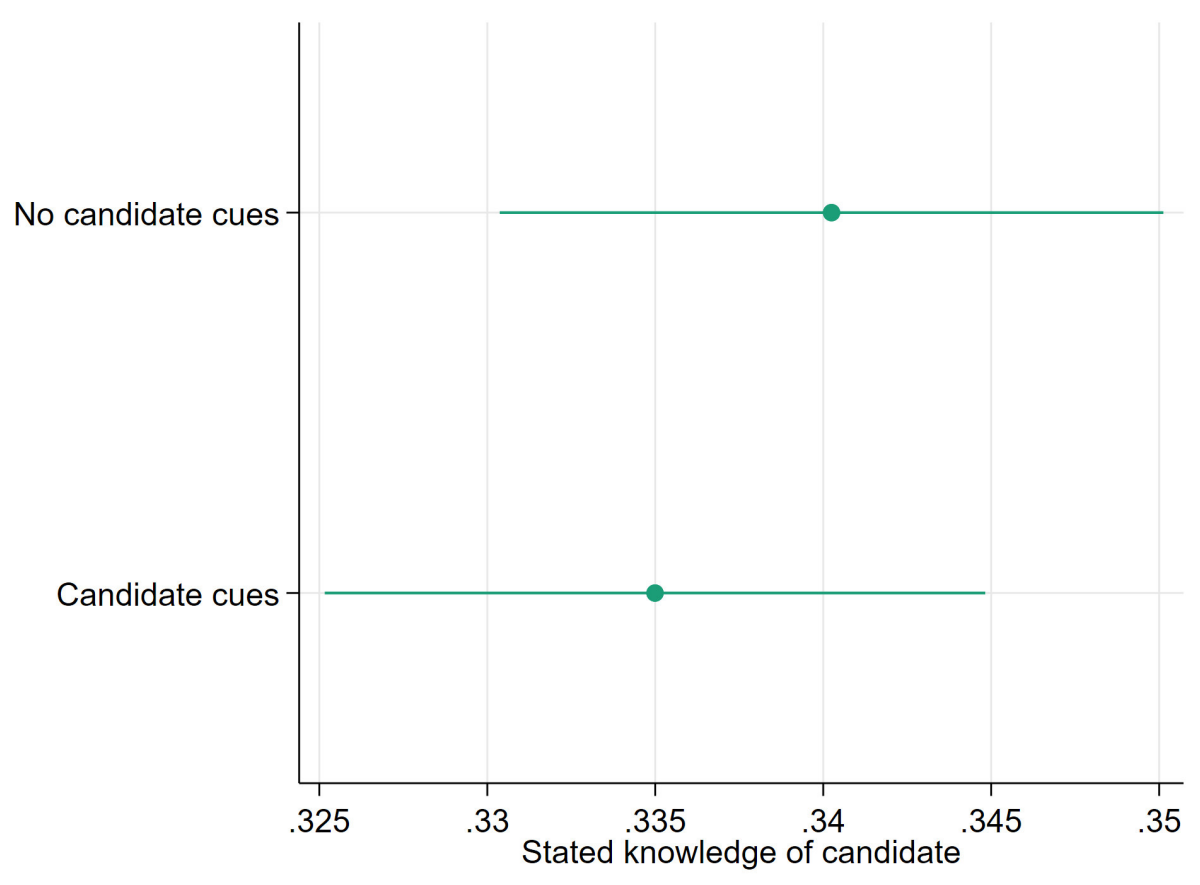

Figure A.2: Conditional means for a binary indicator whether respondent states that she does not know a candidate (0) or that she knows a candidate (1) by two experimental conditions (0: no candidate information displayed; 1 : age, residence displayed). 95\% confidence intervals displayed. 


\section{A.5 Items used to calculate the environmental issue position of candidates and respondents}

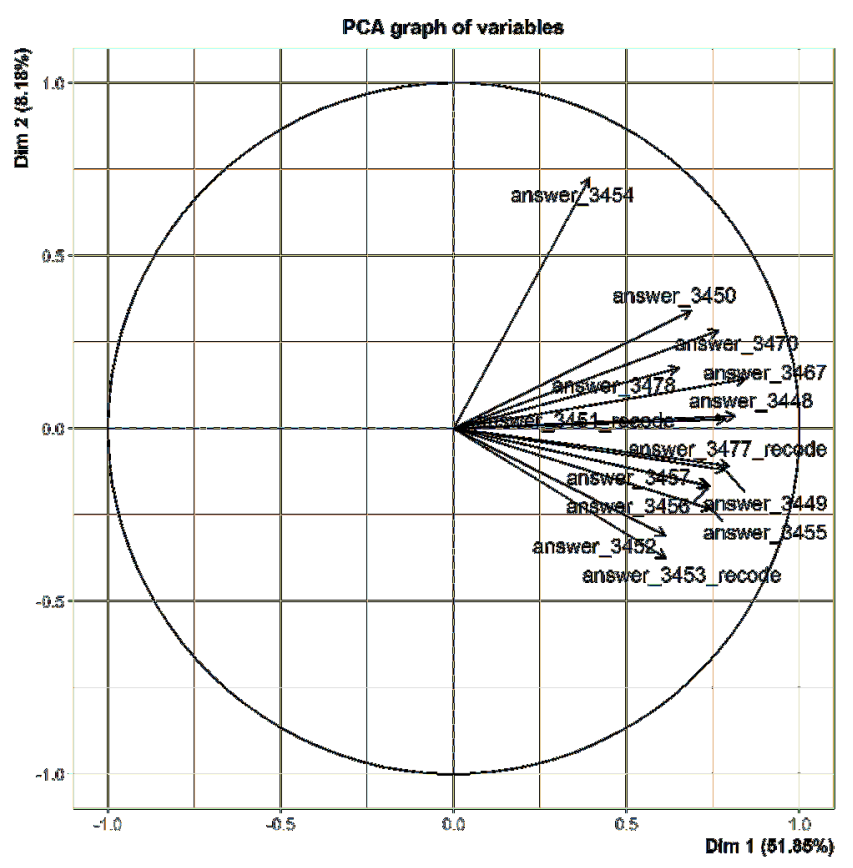

Figure A.3: Factor loadings of the environmental score items

The fourteen items in Table A.4 were chosen by the Smartvote team based on a collection of questions which aim to represent as many aspects of the respective policy dimensions as possible and take into account current issues. Smartvote pretests these items before using them in the final questionnaire for candidates and citizens (Smartvote 2019b). As Figure A.3 shows, the fourteen items load strongly onto one dimension which accounts for $51.85 \%$ of the overall variance. The screeplot in Figure A.4 also supports the notion that the items can be summarised in one dimension. With a standardised Cronbach's alpha of 0.93 , the index based on the 14 items also has high reliability as an additive scale. 
Table A.4: Smartvote Environmental Items

\begin{tabular}{|c|c|c|}
\hline Item & Direction & $\begin{array}{l}\text { Included } \\
\text { in short } \\
\text { index }\end{array}$ \\
\hline $\begin{array}{l}\text { An initiative calls for Switzerland to stop using fossil fuels } \\
\text { by } 2050 \text {. Do you support this proposal? }\end{array}$ & + & $\checkmark$ \\
\hline $\begin{array}{l}\text { Currently, a } \mathrm{CO}_{2} \text { charge is levied on fossil combustibles (e.g. } \\
\text { heating oil, natural gas). Should this charge be extended to } \\
\text { motor fuels (e.g. petrol, diesel)? }\end{array}$ & + & $\checkmark$ \\
\hline $\begin{array}{l}\text { Should the federal government provide more support for } \\
\text { renewable energies? }\end{array}$ & + & \\
\hline Should high traffic motorways be expanded to six lanes? & - & $\checkmark$ \\
\hline $\begin{array}{l}\text { Are you in favour of introducing "Road Pricing" for } \\
\text { motorised individual transport on busy roads? }\end{array}$ & + & \\
\hline $\begin{array}{l}\text { Do you support the relaxation of the current measures to } \\
\text { protect large predators (lynx, wolves, bears)? }\end{array}$ & - & $\checkmark$ \\
\hline $\begin{array}{l}\text { Should the current moratorium on genetically modified } \\
\text { plants and animals in Swiss agriculture be extended beyond } \\
2021 ?\end{array}$ & + & $\checkmark$ \\
\hline $\begin{array}{l}\text { Should direct payments only be granted to farmers that } \\
\text { provide an extended ecological performance record (e.g. no } \\
\text { synthetic pesticides and limited use of antibiotics)? }\end{array}$ & + & \\
\hline $\begin{array}{l}\text { Are you in favour of extending landscape protection (e.g. } \\
\text { stricter rules for building outside existing building zones)? }\end{array}$ & + & \\
\hline $\begin{array}{l}\text { Are you in favour of stricter animal welfare regulations for } \\
\text { livestock (e.g. permanent access to outdoor areas)? }\end{array}$ & + & \\
\hline $\begin{array}{l}\text { An initiative calls for liability rules for Swiss companies with } \\
\text { regard to compliance with human rights and environmental } \\
\text { standards abroad to be tightened. Do you support this } \\
\text { proposal? }\end{array}$ & + & \\
\hline $\begin{array}{l}\text { What is your position the following statement: "Stronger } \\
\text { environmental protection is necessary, even if its application } \\
\text { limits economic growth." }\end{array}$ & + & \\
\hline $\begin{array}{l}\text { Should the federal government spend more or less in the } \\
\text { area of "Road traffic (motorised individual transport)"? }\end{array}$ & - & \\
\hline $\begin{array}{l}\text { Should the federal government spend more or less in the } \\
\text { area of "Public transport"? }\end{array}$ & + & \\
\hline
\end{tabular}




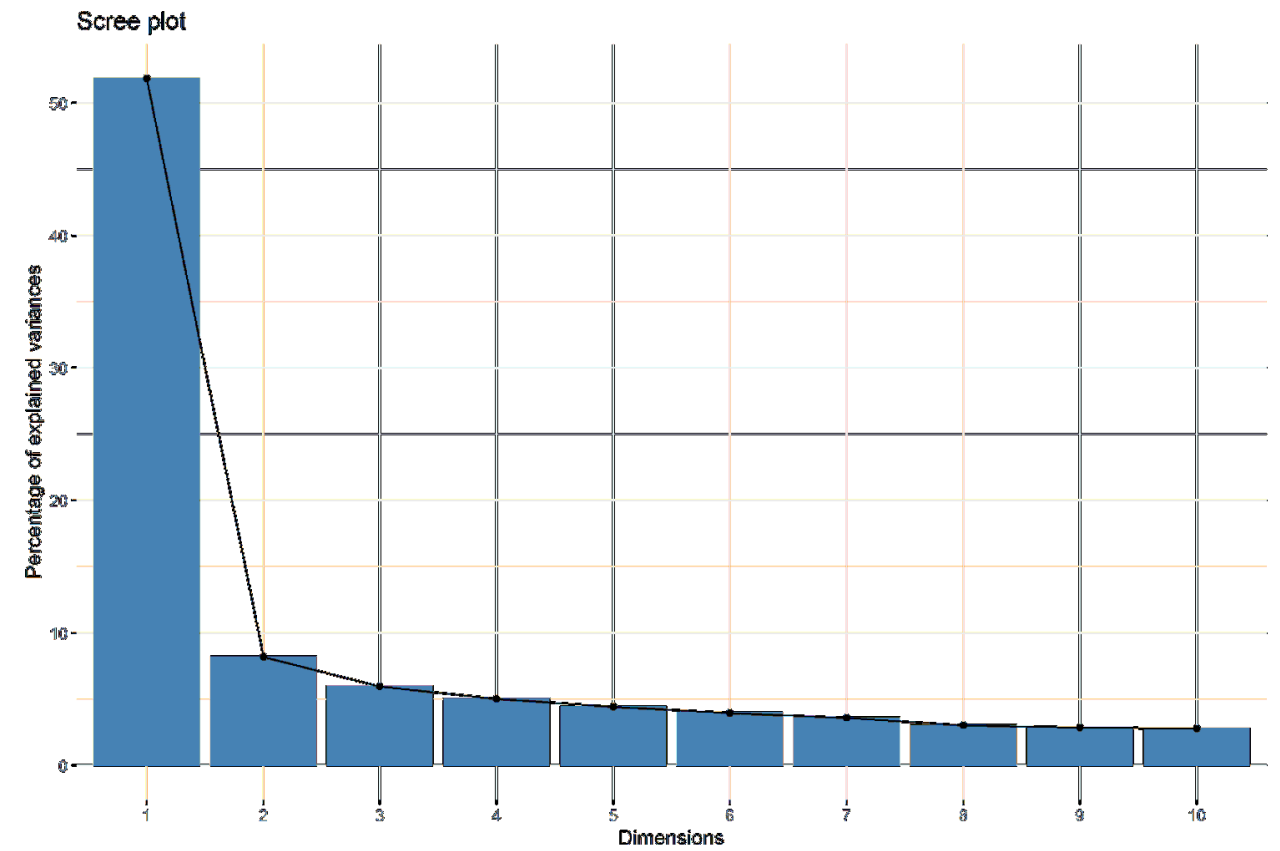

Figure A.4: Factor loadings of the environmental score items 


\section{A.6 Exemplary presentation of survey experiment to respon- dents}

The introductory text before the presented candidates was:

"In the Swiss Parliament, the environment plays an important role. Should environmental protection be expanded or not? This concerns questions such as the promotion of cars or public transport, whether stricter rules on animal and landscape protection should apply, or whether climate protection measures should be implemented quickly or slowly. Candidates for the federal elections, which took place on 20 October 2019, have taken various positions on this issue. We ask you to classify the political positions of these candidates with regard to environmental protection on a scale from $\mathbf{0}$ ("Candidate does not intend to expand environmental protection") to 10 " Candidate intends to significantly expand environmental protection")."

Afterwards, respondents were presented three candidates with either (1) the baseline information on party membership or (2) additional information on age and residence displayed (Figure A.6), (3) party mean displayed, or (4) both age and residence, and party mean displayed (Figure A.5). Then, they were asked "How do you rate $[\mathrm{XXX}]$ ? Does [he/she] want to expand or not to expand environmental protection?" on a scale from 0 to 10 and lastly could state whether they knew the candidate (yes or no) (Figure A.7). The online version of the experiment visually mirrored the print version: respondents saw a candidate and then could indicate their assessment of the candidate's environmental position on a sliders. 


\begin{tabular}{|c|c|c|}
\hline $\begin{array}{l}\text { Manuel Ballmer } \\
\text { (39, Lupsingen) }\end{array}$ & $\begin{array}{c}\text { Thomas de Courten } \\
\text { (53, Rünenberg) }\end{array}$ & $\begin{array}{l}\text { Silvio Fareri } \\
(30, \text { Pratteln })\end{array}$ \\
\hline grünliberale (glp) & $\begin{array}{c}\text { Schweizerische Volkspartei } \\
\text { (SVP) }\end{array}$ & $\begin{array}{c}\text { Christlichdemokratische } \\
\text { Volkspartei (CVP) }\end{array}$ \\
\hline $\begin{array}{l}\text { Position der Partei Grünliberale } \\
\text { zum Ausbau Umweltschutz: } 9,0\end{array}$ & $\begin{array}{l}\text { Position der Partei SVP zum } \\
\text { Ausbau Umweltschutz: } 2,1\end{array}$ & $\begin{array}{c}\text { Position der Partei CVP zum } \\
\text { Ausbau Umweltschutz: } 4,8\end{array}$ \\
\hline 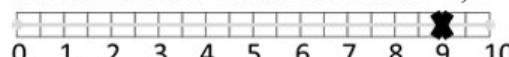 & $4+\boldsymbol{Z} 11+11+11+111$ & 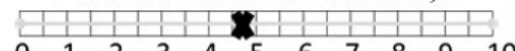 \\
\hline
\end{tabular}

Figure A.5: Survey Experiment: Presentation of Candidates (age and residence, and party mean treatment)

\begin{tabular}{|c|c|c|}
\hline $\begin{array}{c}\text { Tiana Angelina Moser } \\
(40, \text { Zürich) }\end{array}$ & $\begin{array}{c}\text { Thomas Matter } \\
(53, \text { Meilen })\end{array}$ & $\begin{array}{c}\text { Hans-Peter Portmann } \\
\text { (56, Rüschlikon) }\end{array}$ \\
\hline grünliberale (glp) & $\begin{array}{c}\text { Schweizerische Volkspartei } \\
\text { (SVP) }\end{array}$ & FDP.Die Liberalen \\
\hline
\end{tabular}

Figure A.6: Survey Experiment: Presentation of Candidates (age and residence treatment)

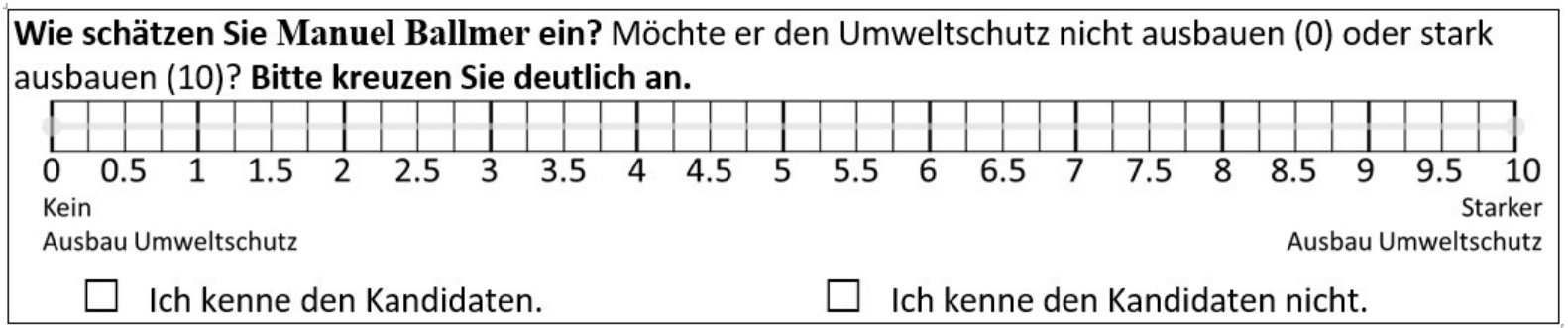

Figure A.7: Survey Experiment: Assessment of Candidates 


\section{A.7 Additional results for $\mathrm{H} 1$}

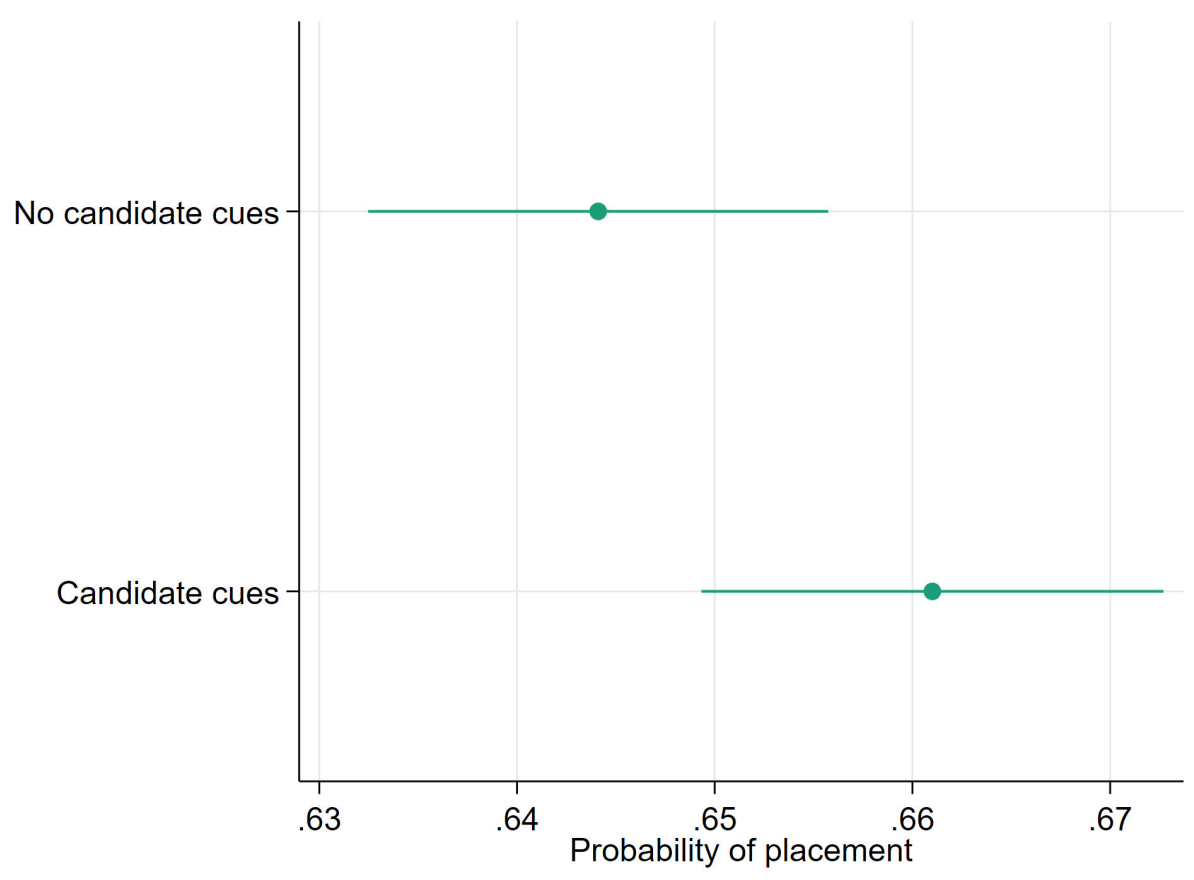

Figure A.8: Treatment increases probability of placement. Conditional means for a binary indicator whether respondent does not place a candidate $(0)$ or does place (1) by two experimental conditions (0: control group, only candidate name and party affiliation or only name, party affiliation and party mean displayed; 1: additionally age and residence displayed. 95\% confidence intervals from robust standard errors shown. $\mathrm{N}=28,770$; clusters $=9,871$. 


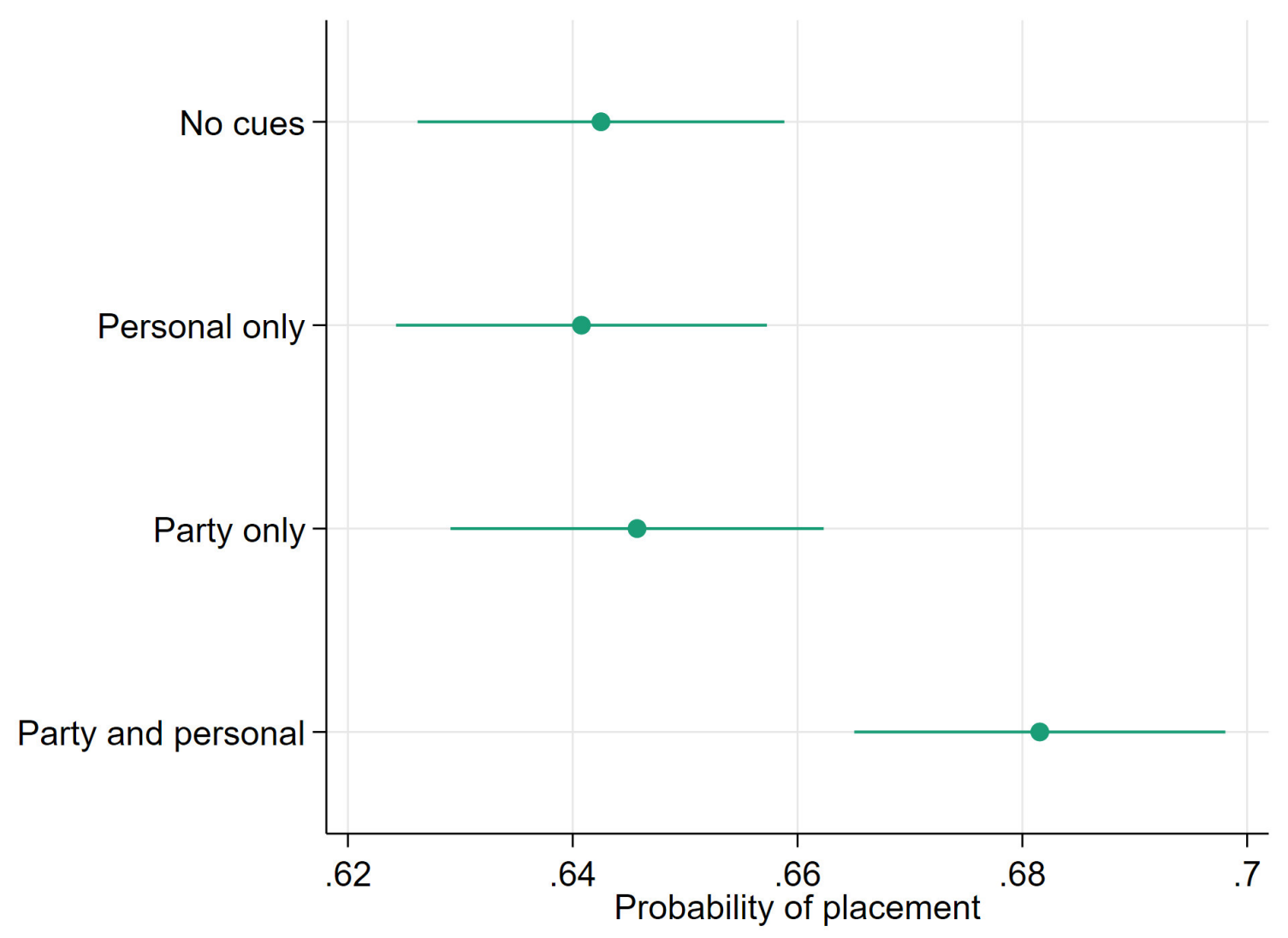

Figure A.9: Treatment increases probability of placement, but only if also given party mean info. Conditional means for a binary indicator whether respondent does not place a candidate (0) or does place (1) by four experimental conditions (0: control group, only candidate name and party affiliation displayed; 1: name, party affiliation, age, residence displayed; 2: name, party affiliation and party mean displayed; 3: name, party affiliation, age, residence and party mean displayed. $95 \%$ confidence intervals from robust standard errors displayed. $\mathrm{N}=28,770$; clusters $=9,871$.

\section{A.8 Robustness tests for $\mathrm{H} 2$}

First of all, Appendix Figure A.10 shows that the mere display of any ballot heuristic does not affect average ratings (as expected, because cues would go in different directions and even if effects were present, they would cancel each other out). As presented in Figures A.11, A.12 and A.13, the general picture of a null-finding on $\mathrm{H} 2$ does not change when differentiating whether a respondent states knowledge of the candidate. To ascertain that there really is a null finding, we present groups of "most likely" candidates (in Appendix Figure A.14). There, we display treatment effects within the subset of candidates where 
both the age and the rurality cue point into the same direction, i.e. we compare young and urban to old and rural candidates within parties. ${ }^{22}$ Still, respondents seemingly do not systematically shift their rating when these cues are revealed, with the notable exception of CVP candidates. Finally, we also tested whether the null-finding depends on the display of the party-mean treatment, which it does not.

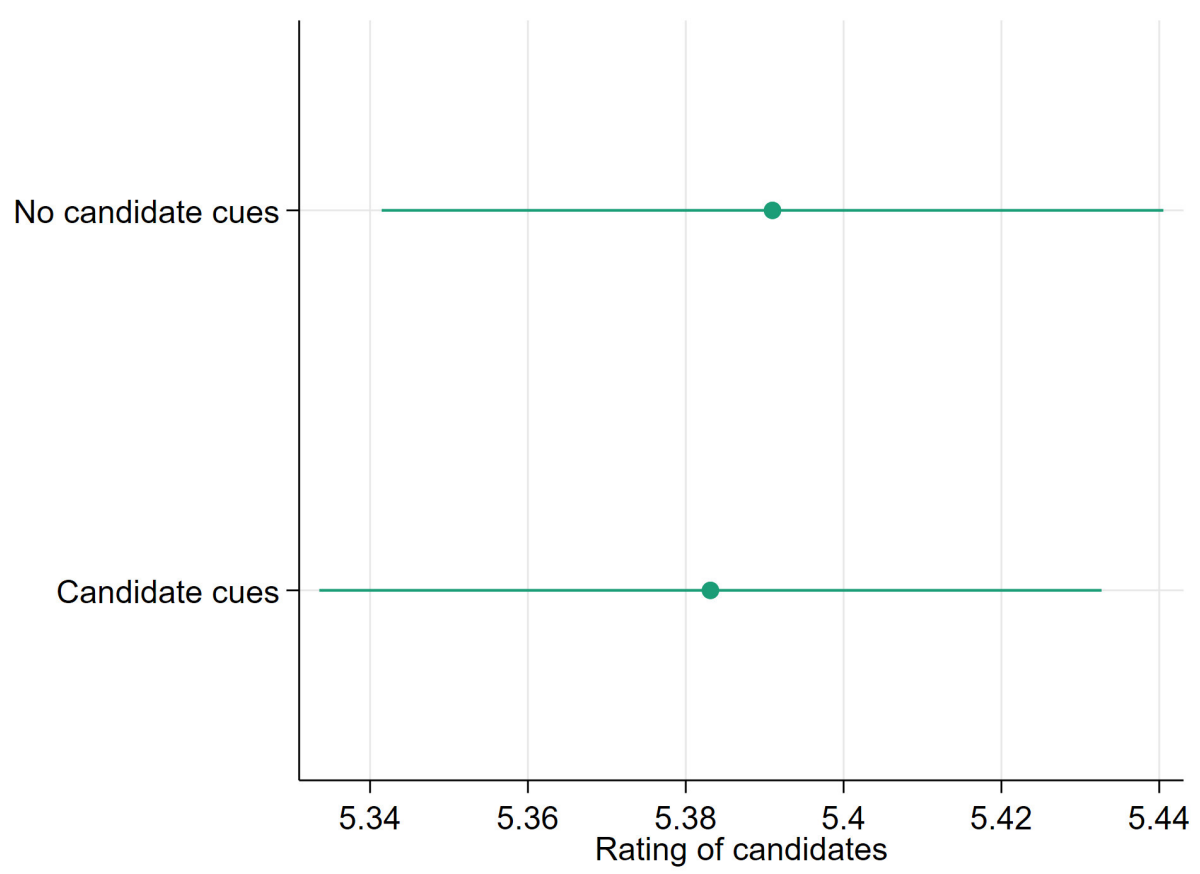

Figure A.10: Treatment has no aggregate effect on rating (pooled for all candidates). Conditional means for 10-point environmental protection scale (1 min, 10 max) by two experimental conditions (0: control group, only candidate name and party affiliation or only name, party affiliation and party mean displayed; 1: additionally age and residence displayed. 95\% confidence intervals from robust standard errors shown. $\mathrm{N}=20,269$; clusters $=8,032$.

22 Some parties have no such candidates, with the respective lines left out in Appendix Figure A.14. 

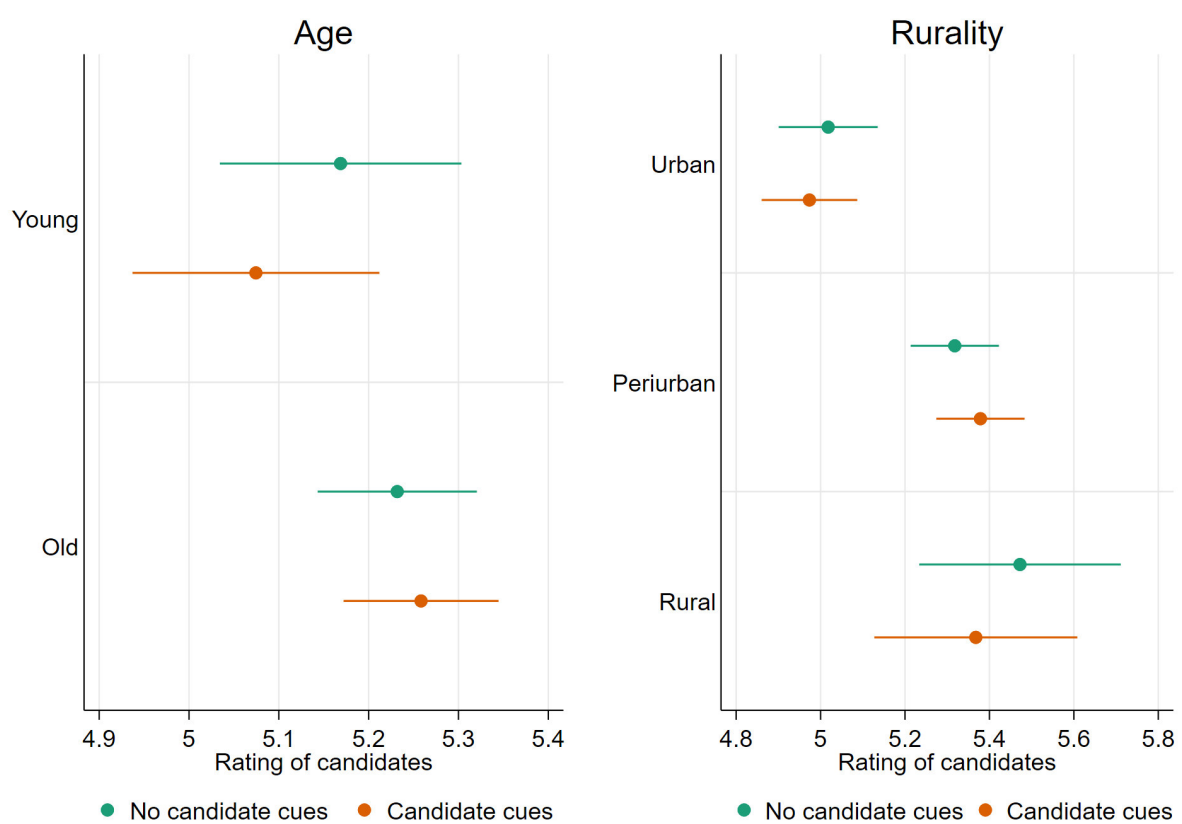

Figure A.11: Display of age/rurality within the subgroup of respondents who state not to know the candidate. $95 \%$ confidence intervals from robust standard errors displayed. 


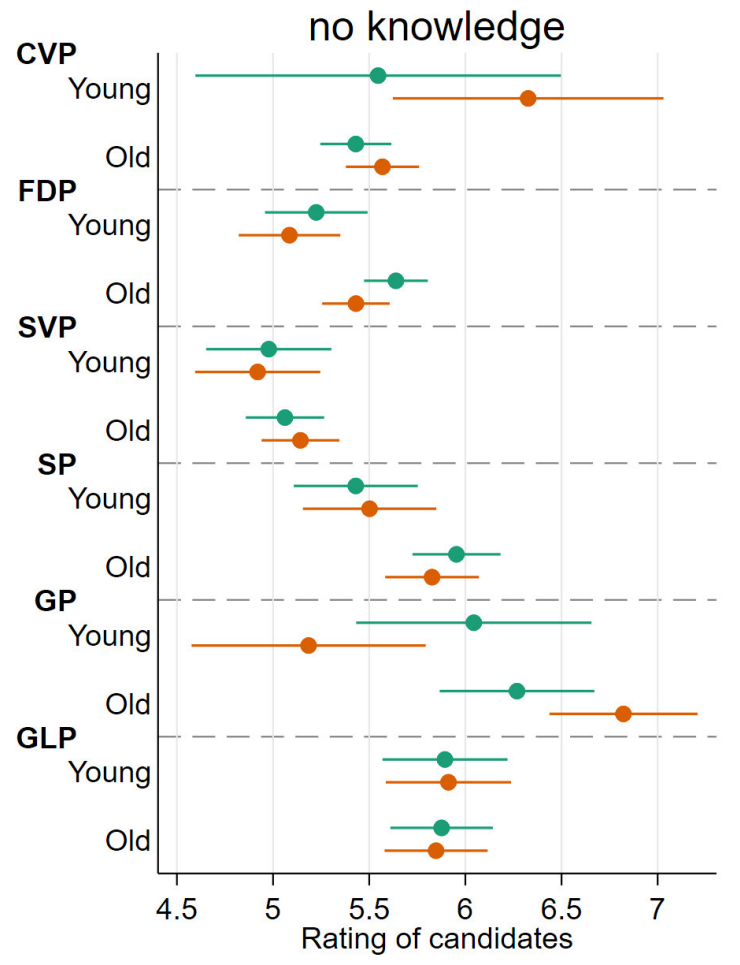

- No candidate cues $\bullet$ Candidate cues

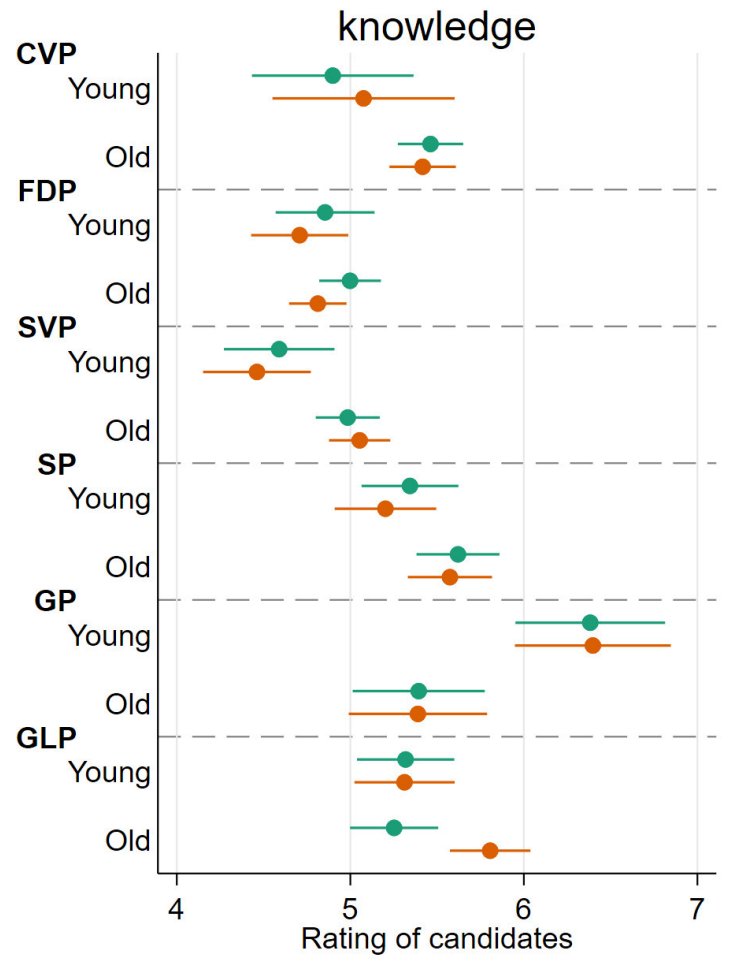

- No candidate cues $\bullet$ Candidate cues

Figure A.12: Treatment interacted with age cues has no effect by party, irrespective of candidate knowledge 


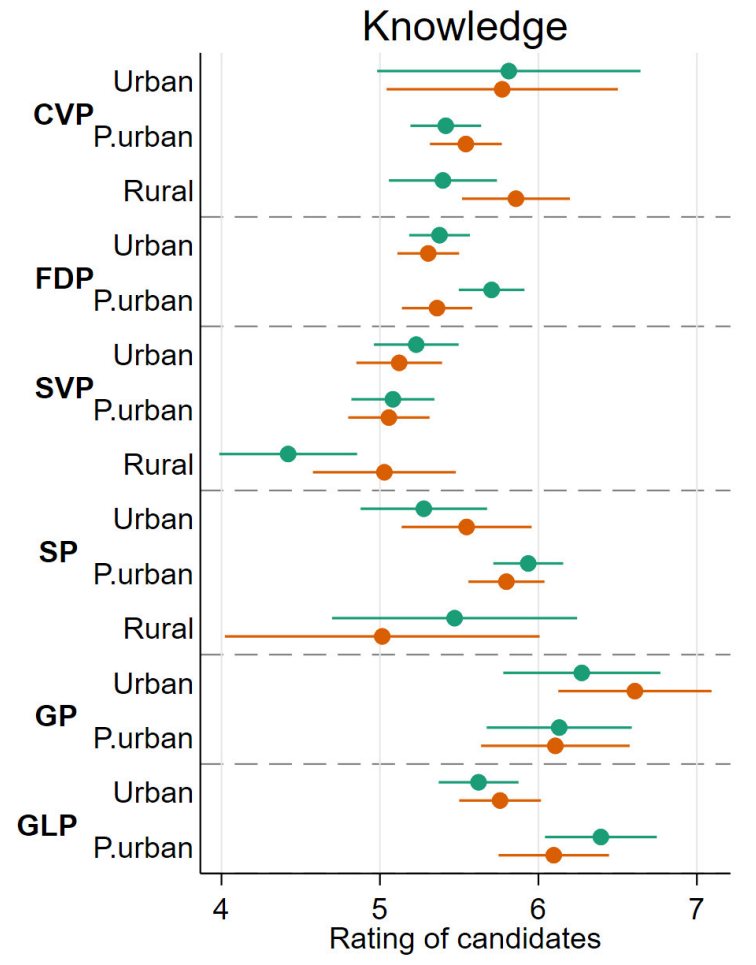

- No candidate cuese Candidate cues

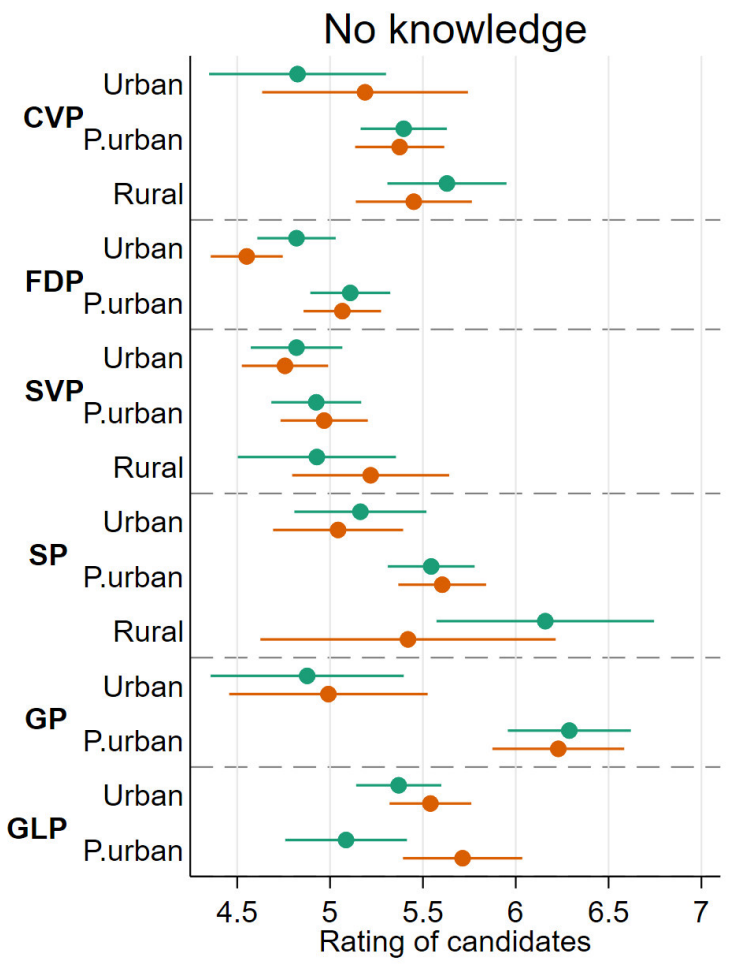

- No candidate cuese Candidate cues

Figure A.13: Treatment interacted with rurality cues has no effect by party, irrespective of candidate knowledge 


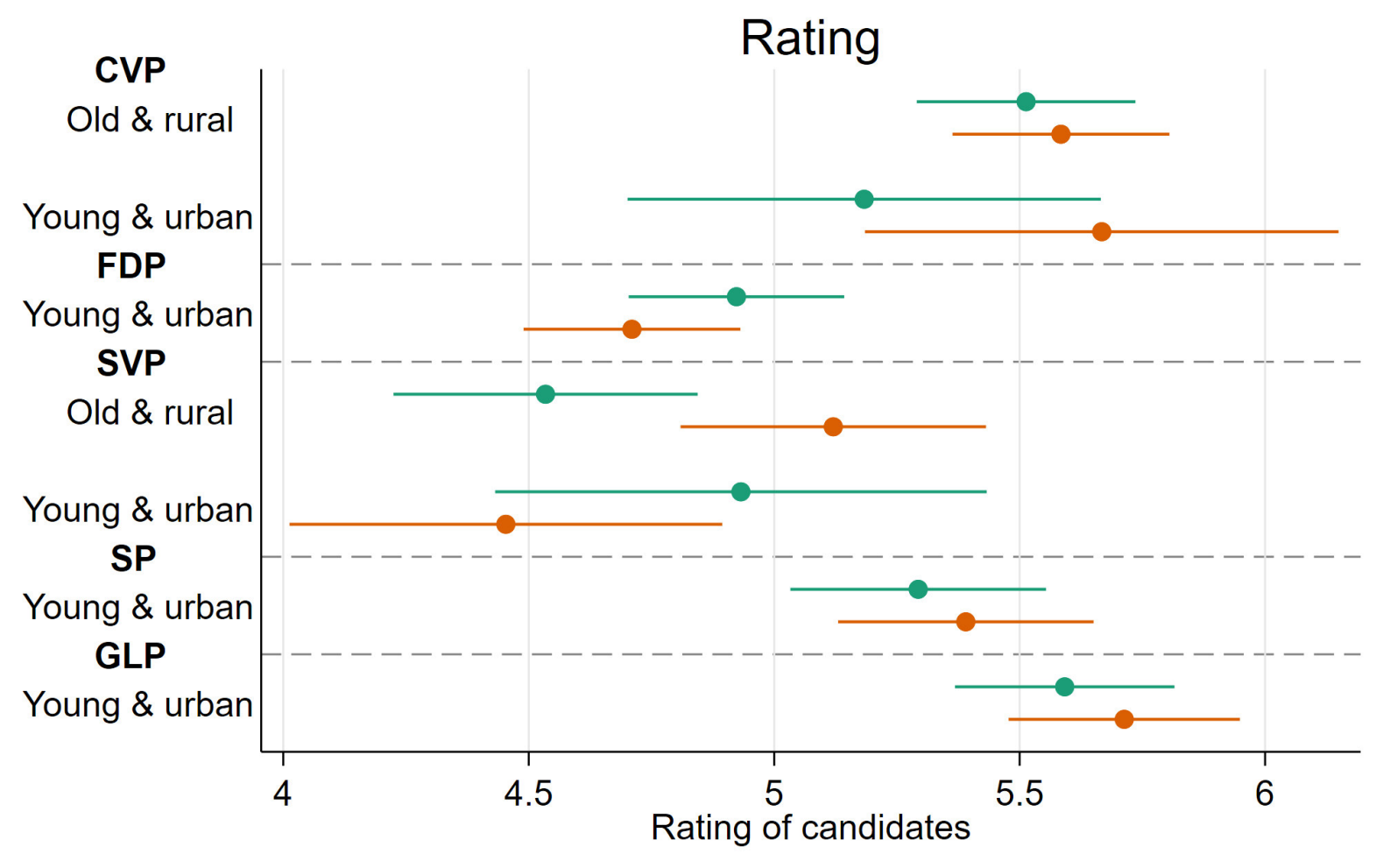

- No candidate cues - Candidate cues

Figure A.14: Treatment has no consistent effect even if cues point in same direction (subset of old/rural candidates and young/urban candidates) 


\section{A.9 Robustness tests for $\mathrm{H3}$}

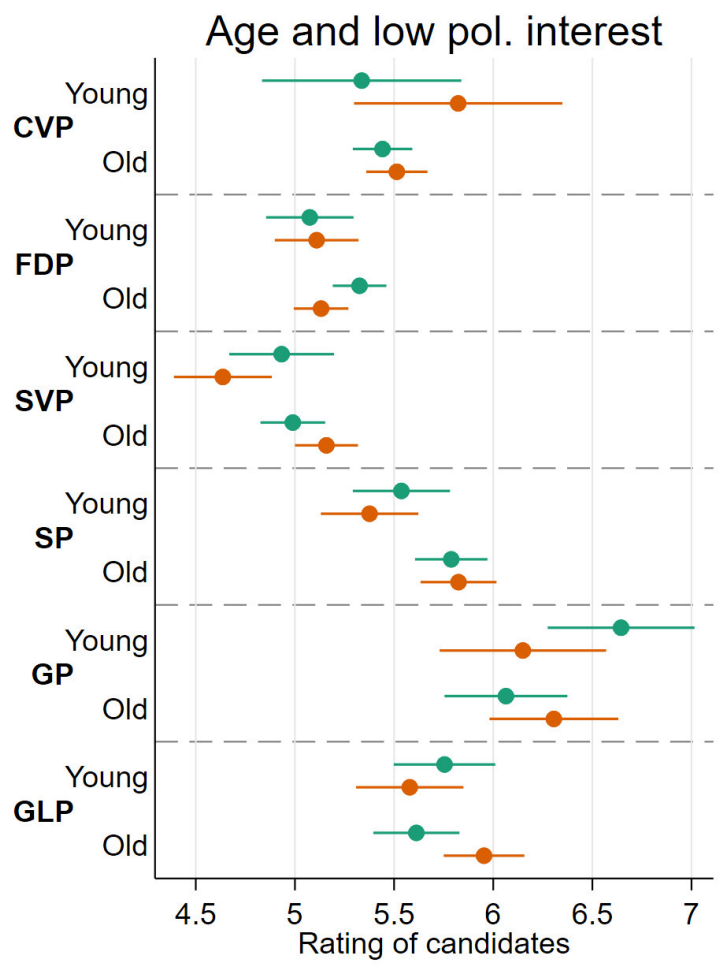

- No candidate cues $\bullet$ Candidate cues

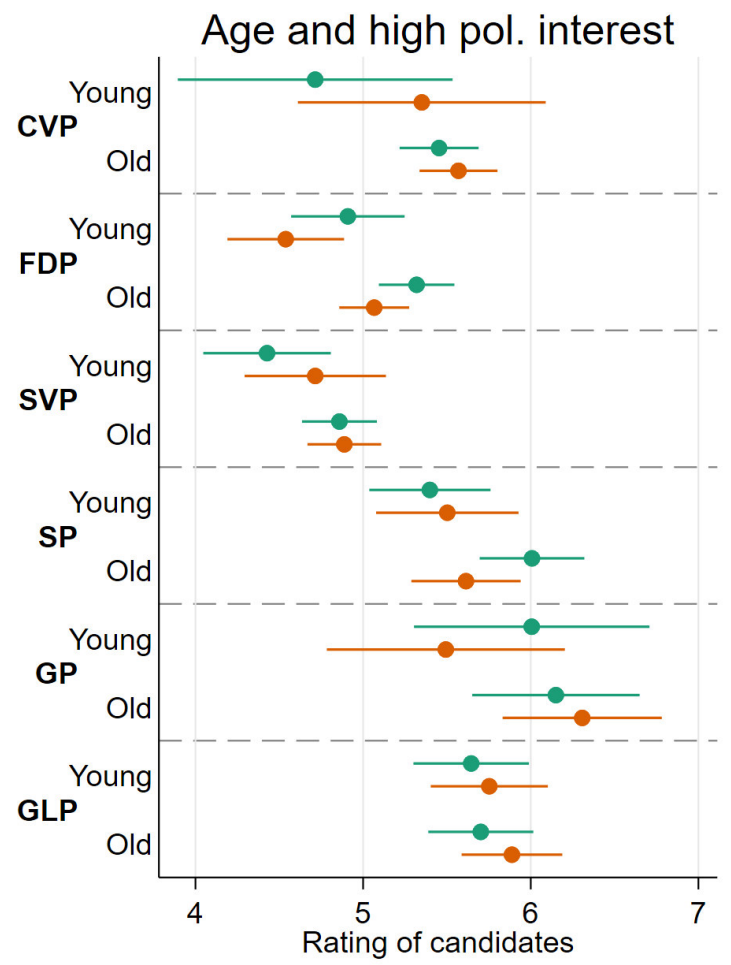

- No candidate cues $\bullet$ Candidate cues

Figure A.15: Treatment by party of candidate, interacted with age cues, has no consistent effect 


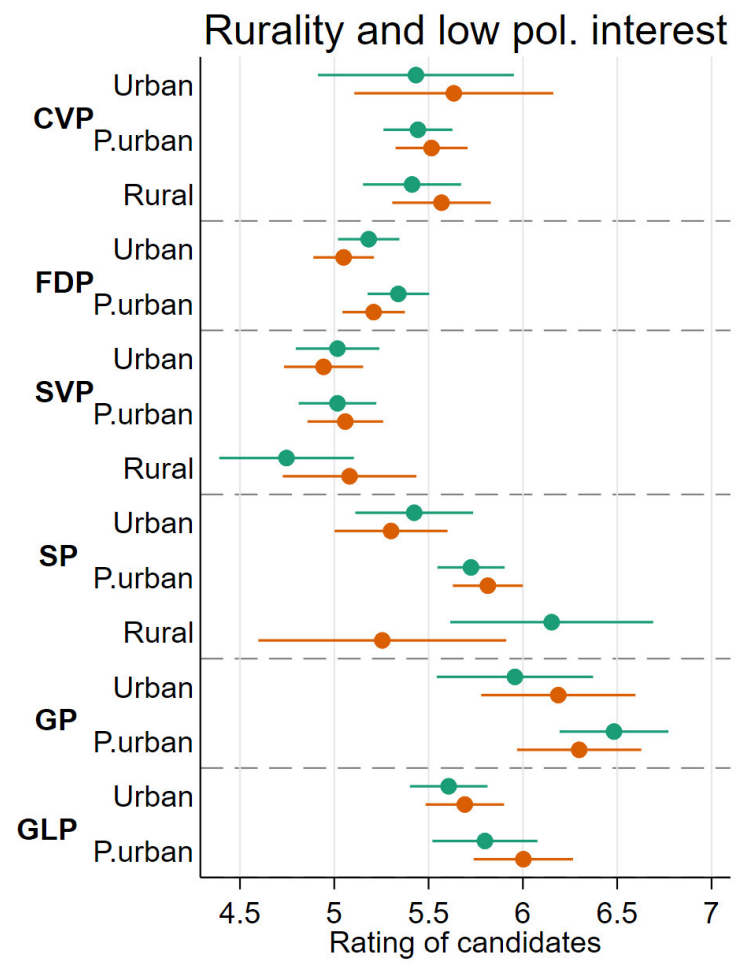

- No candidate cuese Candidate cues

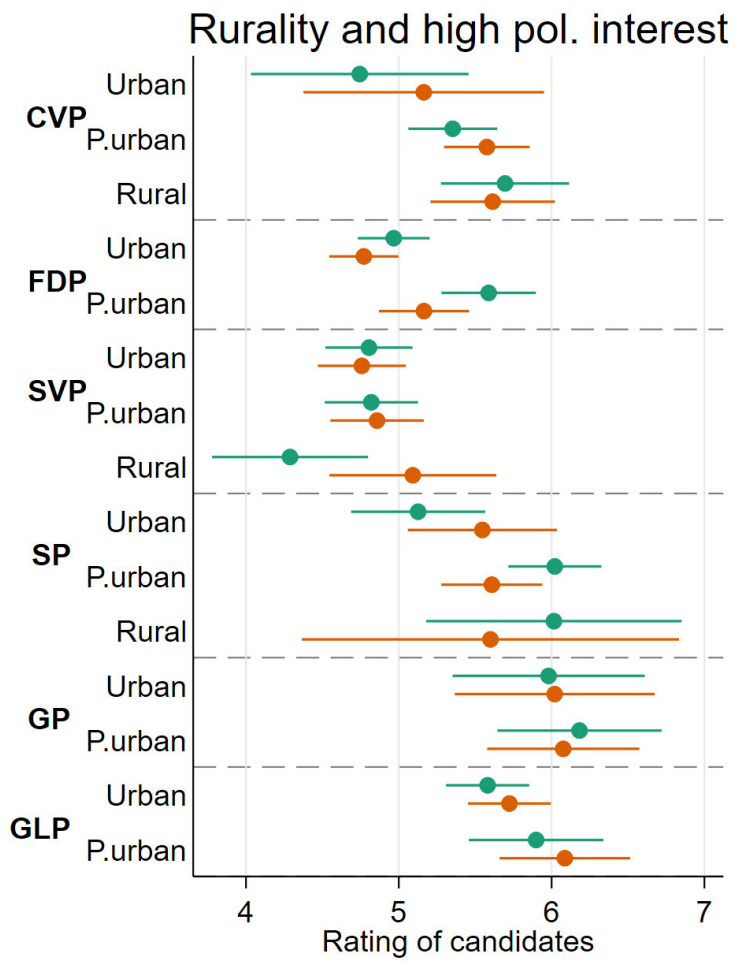

- No candidate cuese Candidate cues

Figure A.16: Treatment by party of candidate, interacted with rurality cues, has no consistent effect 


\section{A.10 Further evidence on the "like-me"-heuristic}

Table A.5: A "like-me"-heuristic?

\begin{tabular}{|c|c|c|c|}
\hline & $\begin{array}{l}(1) \\
\text { rurality }\end{array}$ & $\begin{array}{l}(2) \\
\text { age }\end{array}$ & $\begin{array}{c}(3) \\
\text { both }\end{array}$ \\
\hline Green ego position $=1$ & $\begin{array}{c}-0.343^{* * *} \\
(0.0725)\end{array}$ & $\begin{array}{c}-0.312^{* * *} \\
(0.0644)\end{array}$ & $\begin{array}{c}-0.328^{* * *} \\
(0.0568)\end{array}$ \\
\hline Candidate corresponds to ego $=1$ & $\begin{array}{c}0.0910 \\
(0.0755)\end{array}$ & $\begin{array}{c}0.0518 \\
(0.0773)\end{array}$ & $\begin{array}{c}0.113 \\
(0.0969)\end{array}$ \\
\hline Green ego position $=1 \times$ Candidate corresponds to ego $=1$ & $\begin{array}{r}-0.0481 \\
(0.104)\end{array}$ & $\begin{array}{l}-0.128 \\
(0.106)\end{array}$ & $\begin{array}{l}-0.173 \\
(0.134)\end{array}$ \\
\hline Cues displayed $=1$ & $\begin{array}{l}-0.0112 \\
(0.0751)\end{array}$ & $\begin{array}{c}0.0172 \\
(0.0679)\end{array}$ & $\begin{array}{l}-0.0112 \\
(0.0600)\end{array}$ \\
\hline Green ego position $=1 \times$ Cues displayed $=1$ & $\begin{array}{c}0.00743 \\
(0.103)\end{array}$ & $\begin{array}{l}-0.0524 \\
(0.0911)\end{array}$ & $\begin{array}{c}-0.00886 \\
(0.0804)\end{array}$ \\
\hline Candidate corresponds to ego $=1 \times$ Cues displayed $=1$ & $\begin{array}{c}-0.0654 \\
(0.108)\end{array}$ & $\begin{array}{l}-0.166 \\
(0.111)\end{array}$ & $\begin{array}{l}-0.164 \\
(0.143)\end{array}$ \\
\hline Green ego position $=1 \times$ Candidate corresponds to ego $=1 \times$ Cues displayed $=1$ & $\begin{array}{c}0.133 \\
(0.148)\end{array}$ & $\begin{array}{c}0.327^{*} \\
(0.151)\end{array}$ & $\begin{array}{l}0.422^{*} \\
(0.195)\end{array}$ \\
\hline Constant & $\begin{array}{l}5.544^{* * *} \\
(0.0535)\end{array}$ & $\begin{array}{l}5.569^{* * *} \\
(0.0482)\end{array}$ & $\begin{array}{l}5.565^{* * *} \\
(0.0427)\end{array}$ \\
\hline $\mathrm{N}$ & 20067 & 20170 & 20041 \\
\hline
\end{tabular}


Table A.6: "Like-me"-heuristic is more pronounced if party mean treatment is also shown

\begin{tabular}{|c|c|c|c|}
\hline & $\begin{array}{c}\text { (1) } \\
\text { rurality }\end{array}$ & $\begin{array}{l}(2) \\
\text { age }\end{array}$ & $\begin{array}{c}(3) \\
\text { both }\end{array}$ \\
\hline Green ego position $=1$ & $\begin{array}{c}-0.0805 \\
(0.103)\end{array}$ & $\begin{array}{l}-0.161^{+} \\
(0.0934)\end{array}$ & $\begin{array}{c}-0.109 \\
(0.0805)\end{array}$ \\
\hline Candidate corresponds to ego $=1$ & $\begin{array}{l}0.184^{+} \\
(0.111)\end{array}$ & $\begin{array}{l}0.0377 \\
(0.115)\end{array}$ & $\begin{array}{c}0.229 \\
(0.143)\end{array}$ \\
\hline Green ego position $=1 \times$ Candidate corresponds to ego $=1$ & $\begin{array}{c}-0.254^{+} \\
(0.149)\end{array}$ & $\begin{array}{l}-0.117 \\
(0.155)\end{array}$ & $\begin{array}{c}-0.470^{*} \\
(0.196)\end{array}$ \\
\hline Cues displayed $=1$ & $\begin{array}{l}0.0849 \\
(0.109)\end{array}$ & $\begin{array}{c}0.0371 \\
(0.0987)\end{array}$ & $\begin{array}{c}0.0680 \\
(0.0869)\end{array}$ \\
\hline Green ego position $=1 \times$ Cues displayed $=1$ & $\begin{array}{c}-0.284^{+} \\
(0.145)\end{array}$ & $\begin{array}{l}-0.111 \\
(0.130)\end{array}$ & $\begin{array}{c}-0.193^{+} \\
(0.114)\end{array}$ \\
\hline Candidate corresponds to ego $=1 \times$ Cues displayed $=1$ & $\begin{array}{l}-0.250 \\
(0.158)\end{array}$ & $\begin{array}{l}-0.214 \\
(0.162)\end{array}$ & $\begin{array}{c}-0.545^{* *} \\
(0.206)\end{array}$ \\
\hline Green ego position $=1 \times$ Candidate corresponds to ego $=1 \times$ Cues displayed $=1$ & $\begin{array}{l}0.593^{* *} \\
(0.212)\end{array}$ & $\begin{array}{c}0.333 \\
(0.217)\end{array}$ & $\begin{array}{c}1.043^{* * *} \\
(0.278)\end{array}$ \\
\hline Constant & $\begin{array}{l}5.379^{* * *} \\
(0.0779)\end{array}$ & $\begin{array}{l}5.458^{* * *} \\
(0.0707)\end{array}$ & $\begin{array}{l}5.420^{* * *} \\
(0.0613)\end{array}$ \\
\hline $\mathrm{N}$ & 10063 & 10106 & 10051 \\
\hline
\end{tabular}

Dependent variable: Environmental protection score (scale: 0-10) of candidates. Regressors: Dummy for above median ('green') ego position on environmental protection scale; dummy for correspondence of candidate to ego for age (model 1), rurality (model 2) and both (model 3); dummy for respondent in treatment condition with/without ballot information displayed; twoway and the threeway interactions of these variables. Results for subgroup that received party-mean treatment only. Robust standard errors clustered by respondent displayed in parentheses.

$*(+, * *, * * *)$ indicates $\mathrm{p}<0.05(0.1,0.01,0.001)$ 
Table A.7: "Like-me"-heuristic is more pronounced if respondent reports knowing the candidate

\begin{tabular}{|c|c|c|c|}
\hline & $\begin{array}{c}\text { (1) } \\
\text { rurality }\end{array}$ & $\begin{array}{l}(2) \\
\text { age }\end{array}$ & $\begin{array}{c}(3) \\
\text { both }\end{array}$ \\
\hline Green ego position $=1$ & $\begin{array}{c}-0.175^{+} \\
(0.106)\end{array}$ & $\begin{array}{l}-0.198^{*} \\
(0.0989)\end{array}$ & $\begin{array}{l}-0.219^{*} \\
(0.0855)\end{array}$ \\
\hline Candidate corresponds to ego $=1$ & $\begin{array}{l}0.198^{+} \\
(0.110)\end{array}$ & $\begin{array}{l}0.0727 \\
(0.112)\end{array}$ & $\begin{array}{c}0.146 \\
(0.143)\end{array}$ \\
\hline Green ego position $=1 \times$ Candidate corresponds to ego $=1$ & $\begin{array}{l}-0.245 \\
(0.153)\end{array}$ & $\begin{array}{l}-0.236 \\
(0.153)\end{array}$ & $\begin{array}{c}-0.348^{+} \\
(0.193)\end{array}$ \\
\hline Cues displayed $=1$ & $\begin{array}{c}0.00357 \\
(0.109)\end{array}$ & $\begin{array}{c}-0.00774 \\
(0.100)\end{array}$ & $\begin{array}{l}-0.0579 \\
(0.0878)\end{array}$ \\
\hline Green ego position $=1 \times$ Cues displayed $=1$ & $\begin{array}{r}-0.0447 \\
(0.152)\end{array}$ & $\begin{array}{r}-0.0292 \\
(0.139)\end{array}$ & $\begin{array}{c}0.0318 \\
(0.121)\end{array}$ \\
\hline Candidate corresponds to ego $=1 \times$ Cues displayed $=1$ & $\begin{array}{l}-0.227 \\
(0.158)\end{array}$ & $\begin{array}{l}-0.241 \\
(0.161)\end{array}$ & $\begin{array}{l}-0.240 \\
(0.204)\end{array}$ \\
\hline Green ego position $=1 \times$ Candidate corresponds to ego $=1 \times$ Cues displayed $=1$ & $\begin{array}{l}0.423^{+} \\
(0.221)\end{array}$ & $\begin{array}{c}0.473^{*} \\
(0.223)\end{array}$ & $\begin{array}{c}0.636^{*} \\
(0.283)\end{array}$ \\
\hline Constant & $\begin{array}{l}5.596^{* * *} \\
(0.0772)\end{array}$ & $\begin{array}{l}5.663^{* * *} \\
(0.0719)\end{array}$ & $\begin{array}{l}5.661^{* * *} \\
(0.0627)\end{array}$ \\
\hline $\mathrm{N}$ & 9040 & 9069 & 9023 \\
\hline
\end{tabular}

Dependent variable: Environmental protection score (scale: 0-10) of candidates. Regressors: Dummy for above median ('green') ego position on environmental protection scale; dummy for correspondence of candidate to ego for age (model 1), rurality (model 2) and both (model 3); dummy for respondent in treatment condition with/without ballot information displayed; twoway and the threeway interactions of these variables. Results for subgroup that reports knowing the candidate only. Robust standard errors clustered by respondent displayed in parentheses.

$*(+, * *, * * *)$ indicates $\mathrm{p}<0.05(0.1,0.01,0.001)$ 


\section{A.11 Evidence from varying age-cutoffs}

We operationalize age-groups in a binary way (cut-off at 45 years, see Appendix Figure A.1p in order to estimate transparent and non-parametric subgroup effects on young vs. old candidates. While this cut-off is data-driven, we want to preclude that the dichotomization at 45 drives our (null) findings (indeed, with a lower cut-off, the binary association between young age and respondents' environmental score (compare Table 1) varies slightly ${ }^{23}$ We therefore test for the robustness of this operationalization strategy with two approaches: First, we shift the binary age cut-off downwards, i.e. we investigate whether obtained estimates would differ if we chose an (arbitrary) cut-off of $44,43, \ldots$ 30. Note that we have few observations for candidates with age below 40 (only $10 \%$ of the sample), and even fewer below 35 (only $5 \%$ of the sample). However, the general picture and our interpretation remains consistent irrespective of the chosen cut-off. As reported in Appendix Figure A.18, even if we zoom in on very young candidates (35 and below), we do not see a significant shift in candidates' evaluation with a revelation of their age. While the coefficients suggest that very young candidates are indeed rated greener (as expected from Hypothesis 2), it needs to be kept in mind that these candidates are a very specific subgroup. First and foremost, all of them are from SP or CVP, since no other party fielded high-listed candidates within the age group below 35). This picture is consistent with effects estimated by party and by knowledge (Appendix Figures A.19 and A.20). Second, we estimated models with A) three-categorical age indicators (up to 45, 46-55, $55+$; this corresponds roughly to tertiles of the age distribution) and B) a continuous age indicator. As displayed in Appendix Table A.8, the model specification does not affect our general conclusion: The revelation of age is not related to a differential evaluation of candidates' environmental score, at least not significantly so, and irrespective of whether we control for party ID, gender and rurality.

23 It is slightly weaker with a cut-off around 30 years, and slightly stronger with a cut-off in the mid-20s. Note, though, that it remains throughout positive and significant (at least when estimated without control variables). 
Table A.8: Robustness tests for main effects of Figure 3 with three-categorical and continouus modelling of age and with and without control variables

\begin{tabular}{|c|c|c|c|c|c|c|}
\hline & $\begin{array}{l}1) \\
\text { Cand. env. score }\end{array}$ & $\begin{array}{l}(2) \\
\text { Cand. env. score }\end{array}$ & $\begin{array}{l}(3) \\
\text { Cand. env. score }\end{array}$ & $\begin{array}{l}\text { (4) } \\
\text { Cand. env. score }\end{array}$ & $\begin{array}{l}(5) \\
\text { Cand. env. score }\end{array}$ & $\begin{array}{l}\text { (6) } \\
\text { Cand. env. score }\end{array}$ \\
\hline Cand. age over $45=0$ & $\begin{array}{l}-0.0858 \\
(0.0575)\end{array}$ & & & $\begin{array}{l}-0.180^{* *} \\
(0.0608)\end{array}$ & & \\
\hline Cues displayed $=1$ & $\begin{array}{c}0.0263 \\
(0.0444)\end{array}$ & $\begin{array}{c}0.0575 \\
(0.0594)\end{array}$ & $\begin{array}{l}-0.346 \\
(0.220)\end{array}$ & $\begin{array}{c}0.0344 \\
(0.0665)\end{array}$ & $\begin{array}{c}0.0561 \\
(0.0775)\end{array}$ & $\begin{array}{l}-0.291 \\
(0.220)\end{array}$ \\
\hline Cand. age over $45=0 \times$ Cues displayed $=1$ & $\begin{array}{c}-0.115 \\
(0.0813)\end{array}$ & & & $\begin{array}{c}-0.100 \\
(0.0828)\end{array}$ & & \\
\hline Cand. age up to 45 & & $\begin{array}{l}-0.0376 \\
(0.0637)\end{array}$ & & & $\begin{array}{l}-0.124^{+} \\
(0.0699)\end{array}$ & \\
\hline Cand. age $46-55$ & & $\begin{array}{c}0.110^{+} \\
(0.0633)\end{array}$ & & & $\begin{array}{c}0.111 \\
(0.0708)\end{array}$ & \\
\hline Cand. age up to $45 \times$ Cues displayed $=1$ & & $\begin{array}{c}-0.146 \\
(0.0904)\end{array}$ & & & $\begin{array}{c}-0.123 \\
(0.0927)\end{array}$ & \\
\hline Cand. age $46-55 \times$ Cues displayed $=1$ & & $\begin{array}{l}-0.0723 \\
(0.0894)\end{array}$ & & & $\begin{array}{l}-0.0516 \\
(0.0925)\end{array}$ & \\
\hline Cand. age & & & $\begin{array}{l}0.000706 \\
(0.00299)\end{array}$ & & & $\begin{array}{c}0.00402 \\
(0.00318)\end{array}$ \\
\hline Cues displayed $=1 \times$ Cand. age & & & $\begin{array}{c}0.00661 \\
(0.00424)\end{array}$ & & & $\begin{array}{c}0.00575 \\
(0.00430)\end{array}$ \\
\hline Periurban & & & & $\begin{array}{c}0.189^{* *} \\
(0.0588)\end{array}$ & $\begin{array}{c}0.184^{* *} \\
(0.0589)\end{array}$ & $\begin{array}{l}0.223^{* * *} \\
(0.0578)\end{array}$ \\
\hline Rural & & & & $\begin{array}{l}0.0958 \\
(0.103)\end{array}$ & $\begin{array}{c}0.140 \\
(0.106)\end{array}$ & $\begin{array}{c}0.108 \\
(0.103)\end{array}$ \\
\hline Periurban $\times$ Cues displayed $=1$ & & & & $\begin{array}{l}-0.0332 \\
(0.0791)\end{array}$ & $\begin{array}{l}-0.0287 \\
(0.0795)\end{array}$ & $\begin{array}{l}-0.0272 \\
(0.0780)\end{array}$ \\
\hline Rural $\times$ Cues displayed $=1$ & & & & $\begin{array}{c}0.116 \\
(0.141)\end{array}$ & $\begin{array}{l}0.0996 \\
(0.145)\end{array}$ & $\begin{array}{c}0.107 \\
(0.142)\end{array}$ \\
\hline FDP & & & & $\begin{array}{l}-0.184^{* *} \\
(0.0671)\end{array}$ & $\begin{array}{l}-0.174^{* *} \\
(0.0674)\end{array}$ & $\begin{array}{l}-0.203^{* *} \\
(0.0670)\end{array}$ \\
\hline SVP & & & & $\begin{array}{c}-0.477^{* * *} \\
(0.0642)\end{array}$ & $\begin{array}{c}-0.502^{* * *} \\
(0.0660)\end{array}$ & $\begin{array}{c}-0.479^{* * *} \\
(0.0643)\end{array}$ \\
\hline SP & & & & $\begin{array}{c}0.207^{* *} \\
(0.0727)\end{array}$ & $\begin{array}{c}0.182^{*} \\
(0.0743)\end{array}$ & $\begin{array}{c}0.212^{* *} \\
(0.0733)\end{array}$ \\
\hline GP & & & & $\begin{array}{l}0.811^{* * *} \\
(0.0928)\end{array}$ & $\begin{array}{l}0.828^{* * *} \\
(0.0934)\end{array}$ & $\begin{array}{l}0.764^{* * *} \\
(0.0929)\end{array}$ \\
\hline GLP & & & & $\begin{array}{l}0.391^{* * *} \\
(0.0758)\end{array}$ & $\begin{array}{l}0.379^{* * *} \\
(0.0762)\end{array}$ & $\begin{array}{l}0.397^{* * *} \\
(0.0764)\end{array}$ \\
\hline Cand. female & & & & $\begin{array}{c}0.135^{* *} \\
(0.0476)\end{array}$ & $\begin{array}{c}0.126^{* *} \\
(0.0480)\end{array}$ & $\begin{array}{c}0.0958^{*} \\
(0.0469)\end{array}$ \\
\hline Constant & $\begin{array}{l}5.417^{* * *} \\
(0.0314)\end{array}$ & $\begin{array}{l}5.368^{* * *} \\
(0.0418)\end{array}$ & $\begin{array}{c}5.355^{* * *} \\
(0.155)\end{array}$ & $\begin{array}{l}5.285^{* * *} \\
(0.0718)\end{array}$ & $\begin{array}{l}5.245^{* * *} \\
(0.0765)\end{array}$ & $\begin{array}{c}5.032^{* * *} \\
(0.180)\end{array}$ \\
\hline $\mathrm{N}$ & 20269 & 20269 & 20269 & 20163 & 20163 & 20163 \\
\hline
\end{tabular}



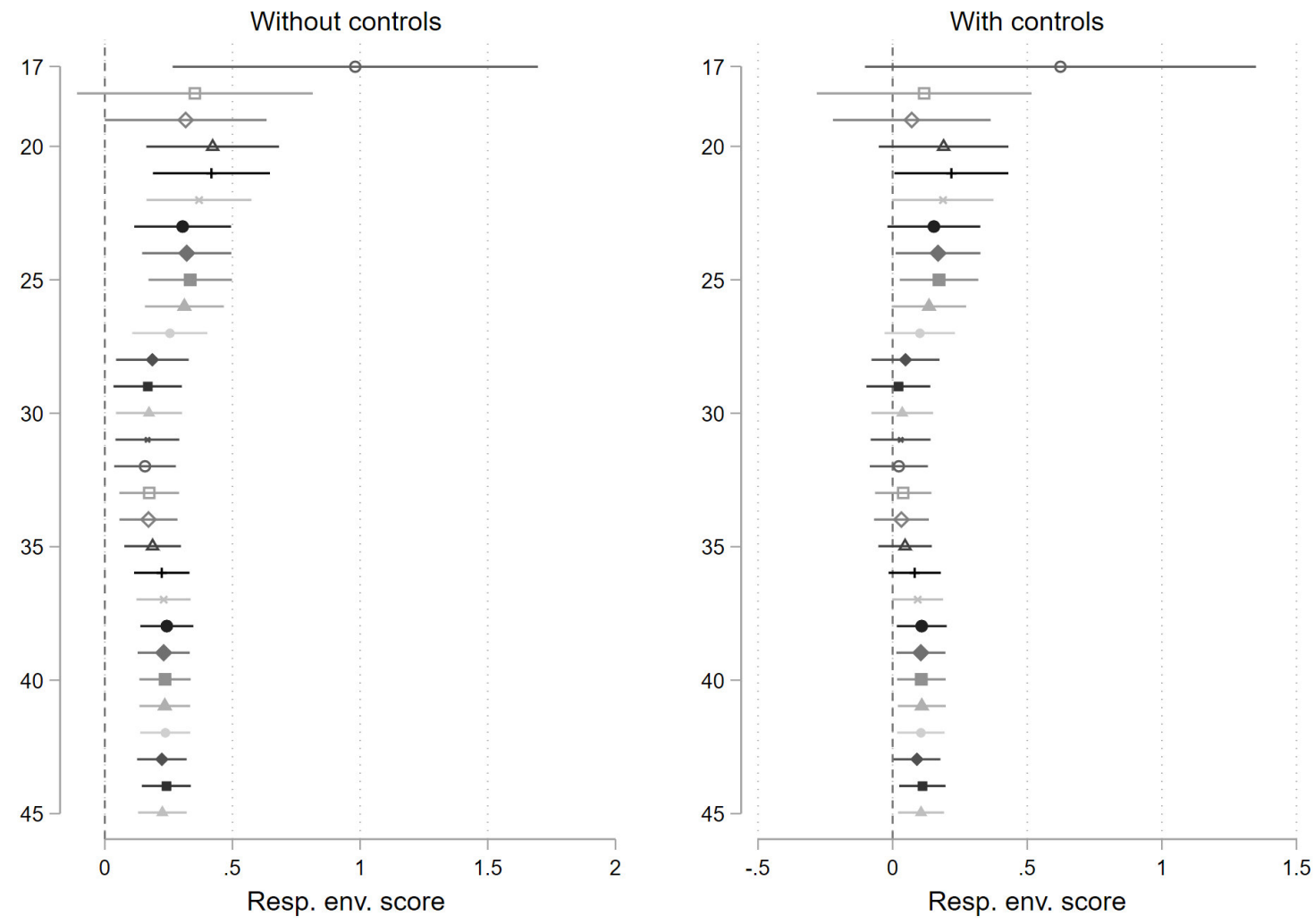

Figure A.17: Age effect of table 1 with age cutoff reduced from 45 to 17 (full empirical lower range) 


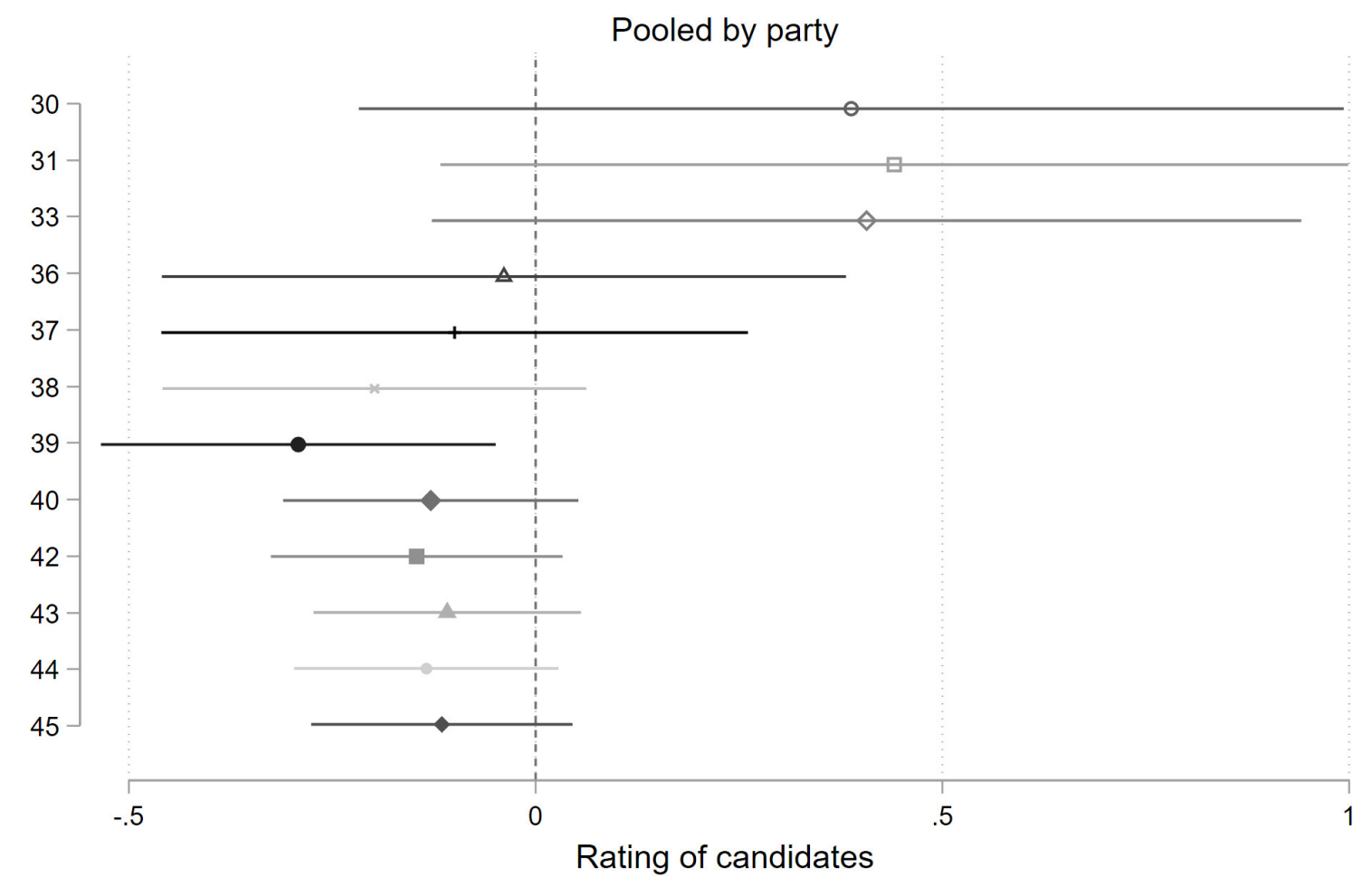

Figure A.18: Age effect of figure 3 (interaction of treatment with "young age"-indicator, with age-indicator varied from 45 to 30 (full empirical lower range) 

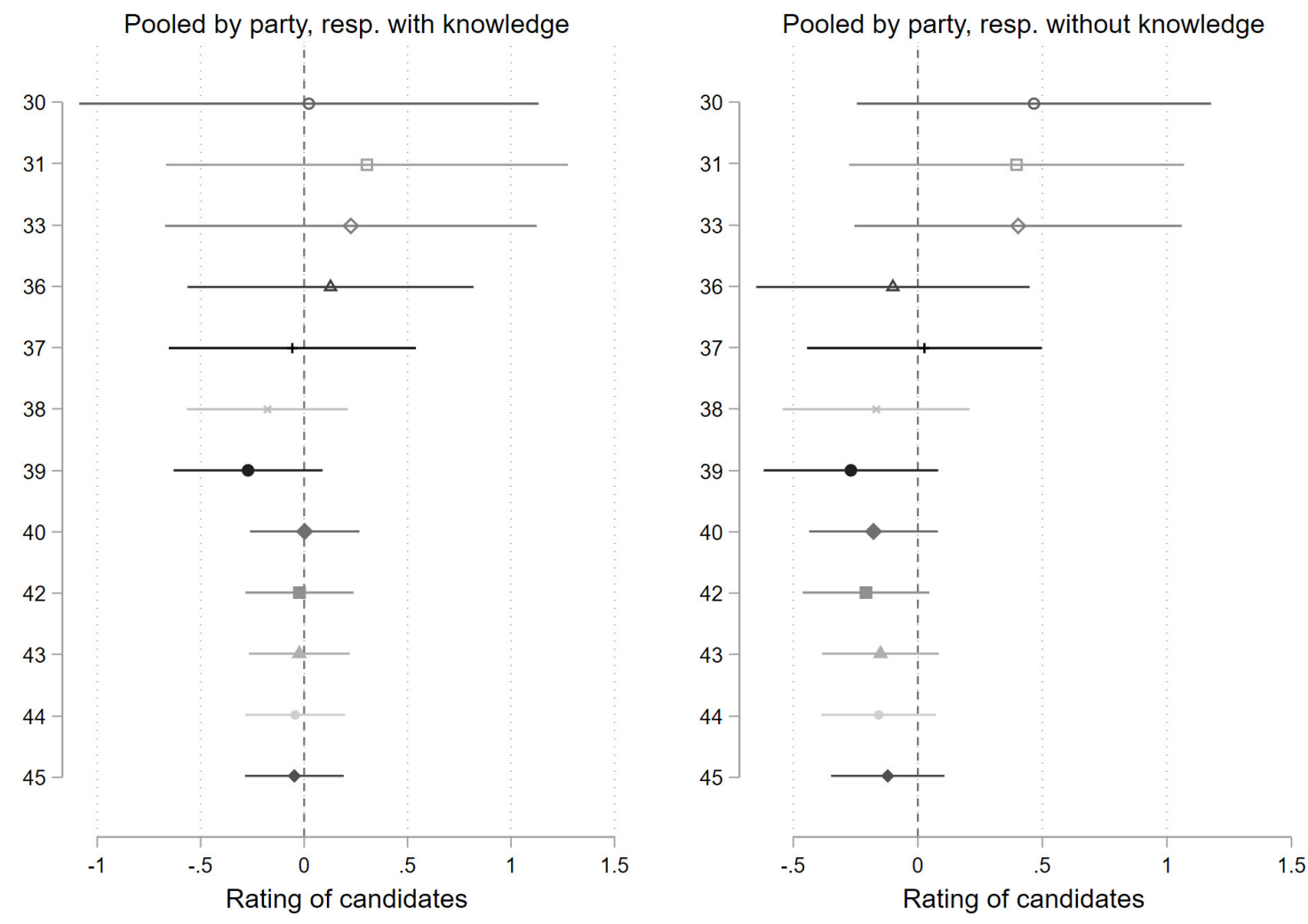

Figure A.19: Age effect of figure 3, left panel (interaction of treatment with "young age"-indicator, with age-indicator varied from 45 to 30 (full empirical lower range), by knowledge of candidate 

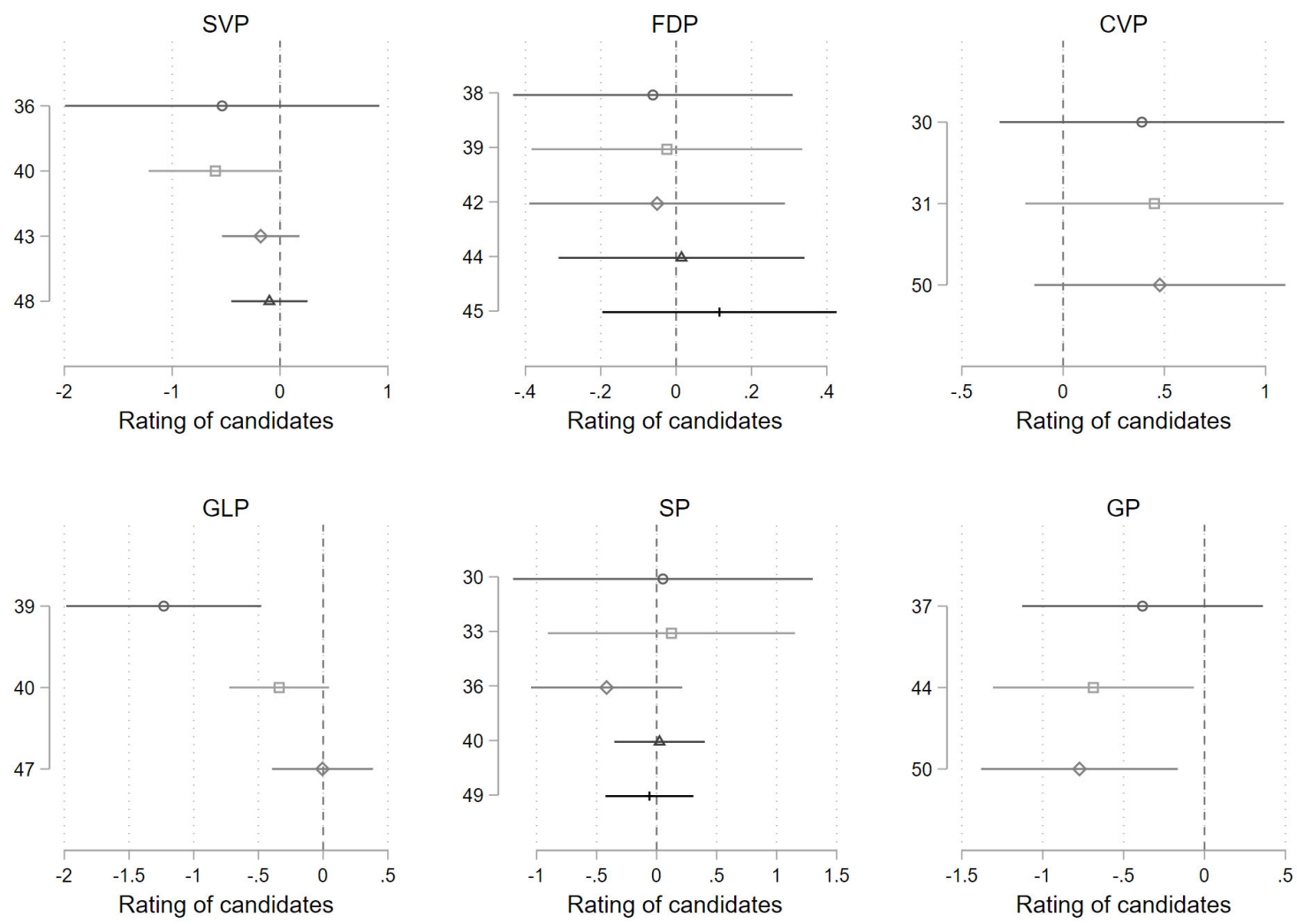

Figure A.20: Age effect of figure 4, left panel (interaction of treatment with "young age"-indicator by party, with age-indicator varied over full empirical lower range of party (as indicated on y-axis)) 


\section{A.12 Regression tables for all figures of the results-section}

Table A.9: Regression table for results presented in Figure 2

\begin{tabular}{|c|c|c|c|c|}
\hline & \multicolumn{2}{|c|}{ No knowledge of candidate } & \multicolumn{2}{|c|}{ Knowledge of candidate } \\
\hline & & $(2)$ & $(3)$ & $(4)$ \\
\hline & Candidate placed & Candidate placed & Candidate placed & Candidate placed \\
\hline Personal only & $\begin{array}{c}-0.000889 \\
(0.0151)\end{array}$ & $\begin{array}{r}-0.00356 \\
(0.0604)\end{array}$ & $\begin{array}{c}0.00475 \\
(0.00851)\end{array}$ & $\begin{array}{l}0.0811 \\
(0.145)\end{array}$ \\
\hline Party only & $\begin{array}{l}0.00121 \\
(0.0152)\end{array}$ & $\begin{array}{l}0.00484 \\
(0.0608)\end{array}$ & $\begin{array}{r}-0.000379 \\
(0.00881)\end{array}$ & $\begin{array}{c}-0.00623 \\
(0.145)\end{array}$ \\
\hline Party and personal & $\begin{array}{c}0.0550^{* * *} \\
(0.0153)\end{array}$ & $\begin{array}{l}0.221^{* * *} \\
(0.0613)\end{array}$ & $\begin{array}{c}0.00601 \\
(0.00840)\end{array}$ & $\begin{array}{c}0.104 \\
(0.145)\end{array}$ \\
\hline Constant & $\begin{array}{l}0.494^{* * *} \\
(0.0107)\end{array}$ & $\begin{array}{c}-0.0260 \\
(0.0428)\end{array}$ & $\begin{array}{c}0.935^{* * *} \\
(0.00622)\end{array}$ & $\begin{array}{c}2.669^{* * *} \\
(0.103)\end{array}$ \\
\hline Estimation model & OLS & logit & OLS & logit \\
\hline $\mathrm{N}$ & 19056 & 19056 & 9714 & 9714 \\
\hline
\end{tabular}


Table A.10: Regression table for results presented in Figure 3

\begin{tabular}{|c|c|c|}
\hline & $\begin{array}{c}\text { (1) } \\
\text { Cand. env. score }\end{array}$ & $\begin{array}{l}(2) \\
\text { Cand. env. score }\end{array}$ \\
\hline Cues displayed $=1$ & $\begin{array}{c}-0.0889 \\
(0.0667)\end{array}$ & $\begin{array}{r}-0.00856 \\
(0.0538)\end{array}$ \\
\hline Cand. age over $45=1$ & $\begin{array}{c}0.0858 \\
(0.0579)\end{array}$ & \\
\hline Cues displayed $=1 \times$ Cand. age over $45=1$ & $\begin{array}{c}0.115 \\
(0.0820)\end{array}$ & \\
\hline Periurban & & $\begin{array}{l}0.264^{* * *} \\
(0.0542)\end{array}$ \\
\hline Rural & & $\begin{array}{l}-0.0211 \\
(0.0946)\end{array}$ \\
\hline Cues displayed $=1 \times$ Periurban & & $\begin{array}{l}-0.0125 \\
(0.0770)\end{array}$ \\
\hline Cues displayed $=1 \times$ Rural & & $\begin{array}{c}0.137 \\
(0.134)\end{array}$ \\
\hline Constant & $\begin{array}{l}5.331^{* * *} \\
(0.0473)\end{array}$ & $\begin{array}{l}5.258^{* * *} \\
(0.0383)\end{array}$ \\
\hline $\mathrm{N}$ & 20269 & 20163 \\
\hline
\end{tabular}


Table A.11: Regression table for results presented in Figure 4

\begin{tabular}{|c|c|c|c|c|c|c|c|c|c|c|c|c|}
\hline & \multicolumn{2}{|c|}{ SVP } & \multicolumn{2}{|c|}{ F FDP } & \multicolumn{2}{|c|}{ CVP } & \multicolumn{2}{|c|}{ glp } & \multicolumn{2}{|c|}{ SP } & \multicolumn{2}{|c|}{ " } \\
\hline & $\begin{array}{l}\text { (1) } \\
\text { Cand. env. score }\end{array}$ & $\begin{array}{l}(2) \\
\text { Cand. env. score }\end{array}$ & $\begin{array}{l}\text { (3) } \\
\text { Cand. env. score }\end{array}$ & $\begin{array}{l}(4) \\
\text { Cand. env. score }\end{array}$ & $\begin{array}{l}\quad(5) \\
\text { Cand. env. score }\end{array}$ & $\begin{array}{l}(6) \\
\text { Cand. env. score }\end{array}$ & $\begin{array}{l}\text { (7) } \\
\text { Cand. env. score }\end{array}$ & $\begin{array}{l}\text { (8) } \\
\text { Cand. env. score }\end{array}$ & $\begin{array}{l}(9) \\
\text { Cand. env. score }\end{array}$ & $\begin{array}{l}(10) \\
\text { Cand. env. score }\end{array}$ & $\begin{array}{l}(11) \\
\text { Cand. env. score }\end{array}$ & $\begin{array}{l}(12) \\
\text { Cand. env. score }\end{array}$ \\
\hline Cues displayed $=1$ & $\begin{array}{l}-0.0617 \\
(0.158)\end{array}$ & $\begin{array}{l}-0.0511 \\
(0.125)\end{array}$ & $\begin{array}{l}-0.0980 \\
(0.135)\end{array}$ & $\begin{array}{c}-0.155 \\
(0.0966)\end{array}$ & $\begin{array}{l}0.535^{+} \\
(0.312)\end{array}$ & $\begin{array}{l}0.294 \\
(0.312)\end{array}$ & $\begin{array}{l}-0.0629 \\
(0.152)\end{array}$ & $\begin{array}{c}0.106 \\
(0.119)\end{array}$ & $\begin{array}{l}-0.0616 \\
(0.153)\end{array}$ & $\begin{array}{l}0.0971 \\
(0.188)\end{array}$ & $\begin{array}{l}-0.470^{+} \\
(0.252)\end{array}$ & $\begin{array}{c}0.172 \\
(0.248)\end{array}$ \\
\hline Cand. age over $45=1$ & $\begin{array}{l}0.211 \\
(0.130)\end{array}$ & & $\begin{array}{l}0.314^{* *} \\
(0.112)\end{array}$ & & $\begin{array}{l}0.339 \\
(0.232)\end{array}$ & & $\begin{array}{l}-0.0578 \\
(0.139)\end{array}$ & & $\begin{array}{l}0.368^{* * *} \\
(0.132)\end{array}$ & & $\begin{array}{l}-0.349 \\
(0.218)\end{array}$ & \\
\hline Cues displayed $=1 \times$ Cand. age over $45=1$ & $\begin{array}{l}0.179 \\
(0.183)\end{array}$ & & $\begin{array}{l}-0.115 \\
(0.159)\end{array}$ & & $\begin{array}{l}-0.451 \\
(0.325)\end{array}$ & & $\begin{array}{l}0.340^{+} \\
(0.197)\end{array}$ & & $\begin{array}{l}-0.0245 \\
(0.192)\end{array}$ & & $\begin{array}{l}0.687^{*} \\
(0.317)\end{array}$ & \\
\hline Periurban & & $\begin{array}{l}0.0230 \\
(0.125)\end{array}$ & & $\begin{array}{l}0.306^{* *+} \\
(0.105)\end{array}$ & & $\begin{array}{l}0.255 \\
(0.230)\end{array}$ & & $\begin{array}{l}0.252^{+} \\
(0.147)\end{array}$ & & $\begin{array}{c}0.514^{4 * * *} \\
(0.154)\end{array}$ & & $\begin{array}{l}0.418^{+} \\
(0.218)\end{array}$ \\
\hline Rural & & $\begin{array}{l}-0.337^{+} \\
(0.174)\end{array}$ & & & & $\begin{array}{c}0.354 \\
(0.244)\end{array}$ & & & & $\begin{array}{l}0.816^{* *} \\
(0.265)\end{array}$ & & \\
\hline Cues displayed $=1 \times$ Periurban & & $\begin{array}{l}0.0932 \\
(0.175)\end{array}$ & & $\begin{array}{l}-0.0527 \\
(0.147)\end{array}$ & & $\begin{array}{l}-0.171 \\
(0.332)\end{array}$ & & $\begin{array}{l}0.0731 \\
(0.204)\end{array}$ & & $\begin{array}{l}-0.148 \\
(0.220)\end{array}$ & & $\begin{array}{l}-0.332 \\
(0.314)\end{array}$ \\
\hline Cues displayed $=1 \times$ Rural & & $\begin{array}{l}0.553^{*} \\
(0.248)\end{array}$ & & & & $\begin{array}{l}-0.223 \\
(0.351)\end{array}$ & & & & $\begin{array}{l}-0.848^{*} \\
(0.420)\end{array}$ & & \\
\hline Constant & $\begin{array}{r}4.725^{* * *} \\
(0.112) \\
\end{array}$ & $\begin{array}{l}4.921^{+* * *} \\
(0.0894) \\
15\end{array}$ & $\begin{array}{l}5.011^{1 * * *} \\
(0.0967)\end{array}$ & $\begin{array}{l}5.10^{0+* *} \\
(0.0692) \\
\end{array}$ & $\begin{array}{r}5.110^{* * * *} \\
(0.223) \\
\end{array}$ & $\begin{array}{c}5.160^{* * *} \\
(0.216) \\
\end{array}$ & $\begin{array}{c}5.713^{* * *} \\
(0.105) \\
\end{array}$ & $\begin{array}{l}5.599^{* * *} \\
(0.0839) \\
\end{array}$ & $\begin{array}{r}5.481^{* * *} \\
(0.105) \\
0298\end{array}$ & $\begin{array}{c}5.293^{* * *} \\
(0.133) \\
\end{array}$ & $\begin{array}{c}6.446^{* * *} \\
(0.172) \\
\end{array}$ & $\begin{array}{r}5.978^{* * *} \\
(0.175) \\
\end{array}$ \\
\hline $\mathrm{N}$ & 4546 & 4546 & 5033 & 5033 & 2950 & 2950 & 3135 & 3135 & 3386 & 3280 & 1219 & 1219 \\
\hline
\end{tabular}

$*(+, * *, * * *)$ indicates $\mathrm{p}<0.05(0.1,0.01,0.001)$ 
Table A.12: Regression table for results presented in Figure 5

\begin{tabular}{lcccc}
\hline \hline & \multicolumn{2}{c}{ Low political interest } & \multicolumn{2}{c}{ High political interest } \\
& Candidate placed & Candidate placed & Candidate placed & Candidate placed \\
\hline \multirow{2}{*}{ Personal only } & -0.000141 & -0.000581 & -0.00854 & -0.0509 \\
& $(0.0145)$ & $(0.0596)$ & $(0.0178)$ & $(0.106)$ \\
Party only & 0.00137 & 0.00564 & -0.0120 & -0.0711 \\
& $(0.0146)$ & $(0.0604)$ & $(0.0178)$ & $(0.105)$ \\
Party and personal & $0.0427^{* *}$ & $0.179^{* *}$ & 0.0121 & 0.0745 \\
& $(0.0147)$ & $(0.0618)$ & $(0.0175)$ & $(0.108)$ \\
Constant & $0.586^{* * *}$ & $0.349^{* * *}$ & $0.791^{* * *}$ & $1.329^{* * *}$ \\
& $(0.0101)$ & $(0.0418)$ & $(0.0125)$ & $(0.0756)$ \\
Estimation model & & & & OLS \\
\hline $\mathrm{N}$ & OLS & logit & 8342 & 8342 \\
\hline \hline
\end{tabular}

Table A.13: Regression table for results presented in Figure 6

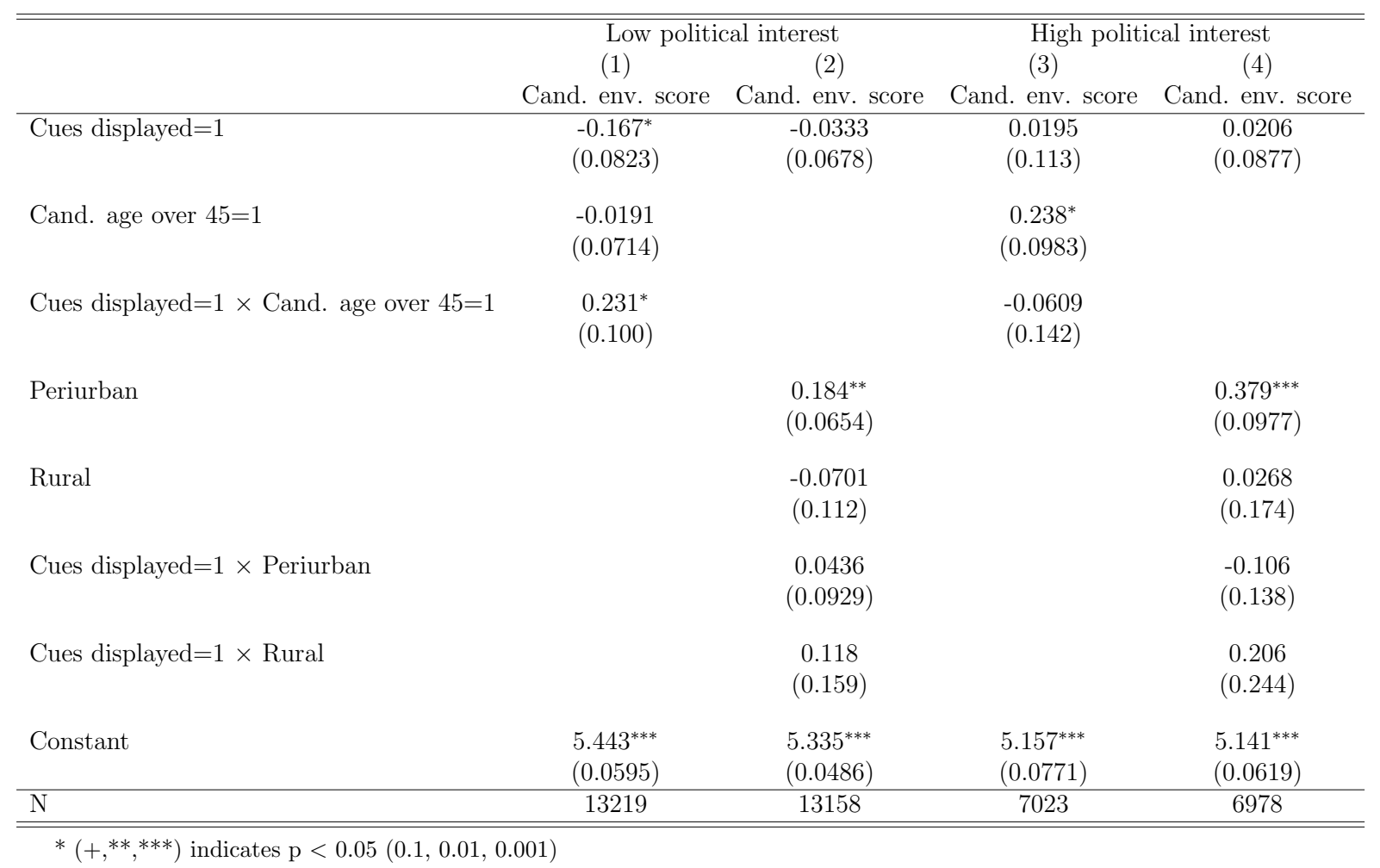

